Article

\title{
A Case Study on Spatio-Temporal Data Mining of Urban Social Management Events Based on Ontology Semantic Analysis
}

\author{
Shaohua Wang ${ }^{1}$, Xianxiong Liu ${ }^{1}$, Haiyin Wang ${ }^{2,3, *}$ and Qingwu Hu 1,3,* (D) \\ 1 School of Remote Sensing and Information Engineering, Wuhan University, Wuhan 430072, China; \\ shwang@whu.edu (S.W.); liuxianxiong@whu.edu.cn (X.L.) \\ 2 Institute of Qingdao Geotechnical Investigation and Surveying, Qingdao 266071, China \\ 3 QingDao Key Laboratory for the Integration and Application of Sea-land Geographical Information, \\ Qingdao 266071, China \\ * Correspondence: why94022@tom.com (H.W.); huqw@whu.edu.cn (Q.H.); Tel.: +86-189-710-70362 (Q.H.)
}

Received: 29 April 2018; Accepted: 15 June 2018; Published: 19 June 2018

\begin{abstract}
The massive urban social management data with geographical coordinates from the inspectors, volunteers, and citizens of the city are a new source of spatio-temporal data, which can be used for the data mining of city management and the evolution of hot events to improve urban comprehensive governance. This paper proposes spatio-temporal data mining of urban social management events (USMEs) based on ontology semantic approach. First, an ontology model for USMES is presented to accurately extract effective social management events from non-structured UMSEs. Second, an explorer spatial data analysis method based on "event-event" and "event-place" from spatial and time aspects is presented to mine the information from UMSEs for the urban social comprehensive governance. The data mining results are visualized as a thermal chart and a scatter diagram for the optimization of the management resources configuration, which can improve the efficiency of municipal service management and municipal departments for decision-making. Finally, the USMEs of Qingdao City in August 2016 are taken as a case study with the proposed approach. The proposed method can effectively mine the management of social hot events and their spatial distribution patterns, which can guide city governance and enhance the city's comprehensive management level.
\end{abstract}

Keywords: city management; spatial-temporal event; ontology; semantic; data mining

\section{Introduction}

Whether the planning and management of a city as a region of human activities is reasonable has seriously affected the long-term development of cities and the happiness index of residents' lives [1-3]. The management and governance of human society is a large and complex project, especially in modern cities. The rapid development of society, complex urban internal space structure, diversified human activities, and human characteristics created by regional factors have posed great challenges to society management [4-7]. The inevitable result on the modern city of human activities is highly clustered. The human civilization, society, economy, and the culture of highly concentrated spaces are an open and complicated system. This openness and complexity have led to complex management of modern cities. Given that digital earth, smart city, and the development of related technologies are put forward, the management and decision-making support of urban social management are possible [8-16]. Importing the digital and intelligent means into the management of cities is the inevitable trend of modern urban social management [17-19]. The way of using the social management 
information database of massive municipal administration departments and analyzing the daily behavior patterns of urban residents are important for urban sustainable development. The spatial distribution characteristics of social security problems and the urban inner space structure can provide decisive support for government departments in providing social management content based on urban production, economy, society, culture, and population management. The data mining of human activities and urban social management events from the city management of mining has become a hot research topic for the urban social management [20-23].

Noulas et al. [24,25] collected tens-of-millions of user check-in data to analyze the user history, moving trajectory for the prediction of the future migration trend of users, and then presented a user interest site recommendation. Ji et al. [26] proposed a themed street clustering method to detect the themed streets of a specific region with the user's mobile phone data from social networks. Farhad and Laylavi [27] designed a multi-elemental location inference method with the geotagged data from Twitter and tried to predict the location of tweets to provide auxiliary data for emergency response. Hu et al. [28] proposed an urban commercial area mining and analysis approach by crawling location-based check-in data from social networks such as Weibo to provide reliable decision-making support in urban planning and economic development. Wang et al. [29] designed a POI significance calculation algorithm using the check-in data from social networks. They analyzed the behavior rules of users, and then studied the distribution rules of urban landmarks on the spatial level, which can be well applied in the intelligent urban management and smart city services.

With the diversity of data sources, for a wide variety of urban social management data, domestic and foreign scholars have designed a variety of analytical methods applied to different areas of urban social management. Zhang et al. [30] used the Markoff forecast model to predict the urban heat island proliferation tendency and provided the decision-making support to mitigate an urban heat island. Kazak [31] integrated scenario analysis, land use modelling and GIS for the assessment of areas for the potential exposure to the Urban Heat Island (UHI) effect, which can be used for the decision making of urban management. Ai [32] established a BP neural network model to forecast the development trend analysis of haze weather using the historical data of 2.5 PM. Zhao et al. [33] analyzed the two-magnitude five pollutant data and researched and analyzed the winter haze event of the North China Plain and its mechanism. Liu et al. [34] constructed the gray Markov chain model, applied it in the traffic volume forecast domain, and realized the traffic volume high accuracy forecast. Das and Winter [35] designed a hybrid knowledge-driven framework, which integrates fuzzy logic and neural networks to analyze vehicle GPS trajectory data and achieve the real-time detection of city traffic patterns; the framework is of great significance to the traffic and transportation planning work of the city. Deng [36] extracted the law of travel behaviors of residents by analyzing people's travel trajectory data. Using the residents' travel habits, they forecast the traffic demand of the city and provide theoretical support for the traffic control department in urban transportation planning. Bergman and Oksanen [37] combined the motion track data and Open Street Map (OSM) and applied them in the automatic travel route planning. Zhang et al. [38] analyzed the various areas of city residents in the travel law and in different periods by processing urban taxi track data in time-sharing segmentation to obtain information from all city residents who commute. Ishikawa and Fujinami [39] collected a large number of mobile phone users who upload travel data and identified the user's circumvention of certain roads through a large number of pedestrian trajectories. They achieved the detection of abnormal roads, such as road pavement cracks, holes, and other issues. Numerous studies show that the spatio-temporal data mining based on social media data and urban management has been fully applied in various fields of city management, such as emergency response [17,40], urban commercial zone and landmark detection for city planning [38,39], environment monitoring [38-40], traffic planning [41-44] and road maintenance [45] etc.

At present, most of the spatio-temporal data mining researches of urban management are based on indirect data, such as social media data; geo-tagged check-in data; travel data from buses, taxis and subways; cell phone calling data etc., which can only analyze the pattern of a certain phenomenon 
in social management from one side [46-50]. The results of indirect spatio-temporal data mining in urban management have some limitations. For example, it can only reflect a small point of the social comprehensive treatment, and the effectiveness of the results needs to be verified through the actual situation. In the process of smart city construction, information technology and mobile internet have been introduced into the field of social management and comprehensive control [51,52]. Thus, the real time collection and analysis of various events during the social management can be generated on time from the Smart City platform. In city management, the primary-level staff and volunteers can obtain a large number of firsthand information such as the status of infrastructure services, public security, disputes and other management logs, which have geographical coordinates. These geotagged social management events become direct spatio-temporal data in urban social management. The data mining results are more reliable than indirect data, do not need verification, and can provide better social management and comprehensive control in decision services of city management.

Therefore, how to make good use of spatio-temporal data from urban social management to explore the existing problems in current social management and comprehensive control, is of great significance. It can help relevant city departments adjust the social management policies and enhance the ability and level of urban management. This paper takes the spatio-temporal data of the urban social management events in the Huangdao District of Qingdao city as the research sample to dig out the spatial distribution pattern and the event distribution pattern of hot events in social management, such as the status of infrastructure services, social security, production safety, disputes, and other incidents. Moreover, analyzing the internal cause and external expression through spatiotemporal visualization to provide decision support for the social management and comprehensive control of the city.

\section{Materials and Methods}

The concept system of social comprehensive governance is huge and complex, and there are various kinds of events. This paper focuses on the extraction of interesting hot events and the spatio-temporal information mining, which is only one of the many entry points in this field. It has a broad research space in the information mining of the social comprehensive management events based on space-time management, whether in content or method. The smart city platform adds a geographic coordinate tag for a variety of events and log data generated from the city management process, but these data records are from inspectors, volunteers in the city management, and even citizens; the events are described as unstructured natural language. This case study proposes a spatio-temporal data mining approach based on the urban social management events to extract unstructured natural language information, to find the event spatio-temporal distribution pattern, and to provide visualized decision support for the social management and comprehensive control of the city. The technical framework of the proposed approach is shown in Figure 1.

Figure 1 shows that the data mining of spatio-temporal urban social management events (USMEs) includes four steps. First, the quality analysis and preprocessing of spatiotemporal data in the social comprehensive management of the city, which excludes invalid data sets, are introduced in Section 2.1. Second, ontology semantic reasoning is used for unstructured natural language records to obtain the structured event database, which is introduced in Section 2.2. Third, through the time and space exploratory analysis of event-events, the time and spatial laws of urban events are extracted, as introduced in Section 2.3. Finally, the mining laws and patterns of urban events are visualized, and the decision support for urban management is provided, as introduced in Section 3. 


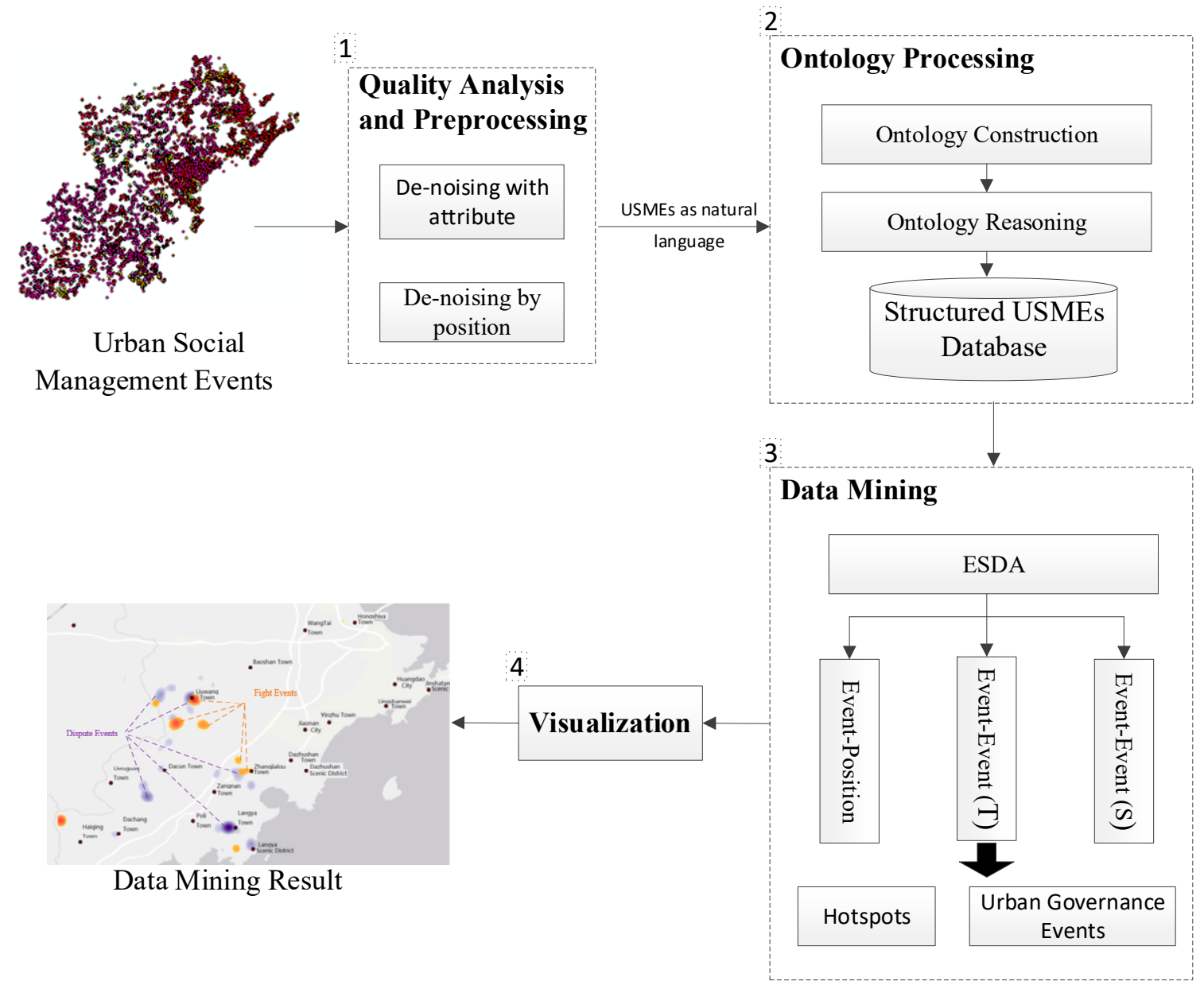

Figure 1. Flowchart of the Proposed Approach.

\subsection{Qualiti Analysis and Noise Processing of USMEs}

The geographical features of urban social management events are composed of spatial characteristics, temporal characteristics and attribute characteristics (Figure 2).

Figure 2 shows that the spatial characteristics of USMEs including the text description of the time occurrence position, the street and area where it belongs, and the specific coordinates of the occurrence position of the event. As the most important spatial characteristic of social management events, location coordinates are the necessary factors for event visualization and subsequent data mining. The temporal characteristic of an event is the occurrence of an event time and date. The attribute characteristics of events describe the non-spatial and non-temporal characteristics of events. It records the basic description of the event in the text form, that is, the kind of social events that have occurred. "Event description" records the principal of the event; text-based event descriptions have high amounts of unstructured event information with great data mining values and are indispensable for the achievement of a complete social management event. Misuse, equipment performance, and failure can cause the data quality problems of social comprehensive management. The data quality of an event must be addressed. A social management event consists of three basic elements: time, place, and event description, which is indispensable. The "event description" field records the principal of the event, which is the heart of the event. When the data is checked, the priority is higher than the time of occurrence and place of the event. Figure 3 shows the quality analysis and processing method of social comprehensive quality events. 


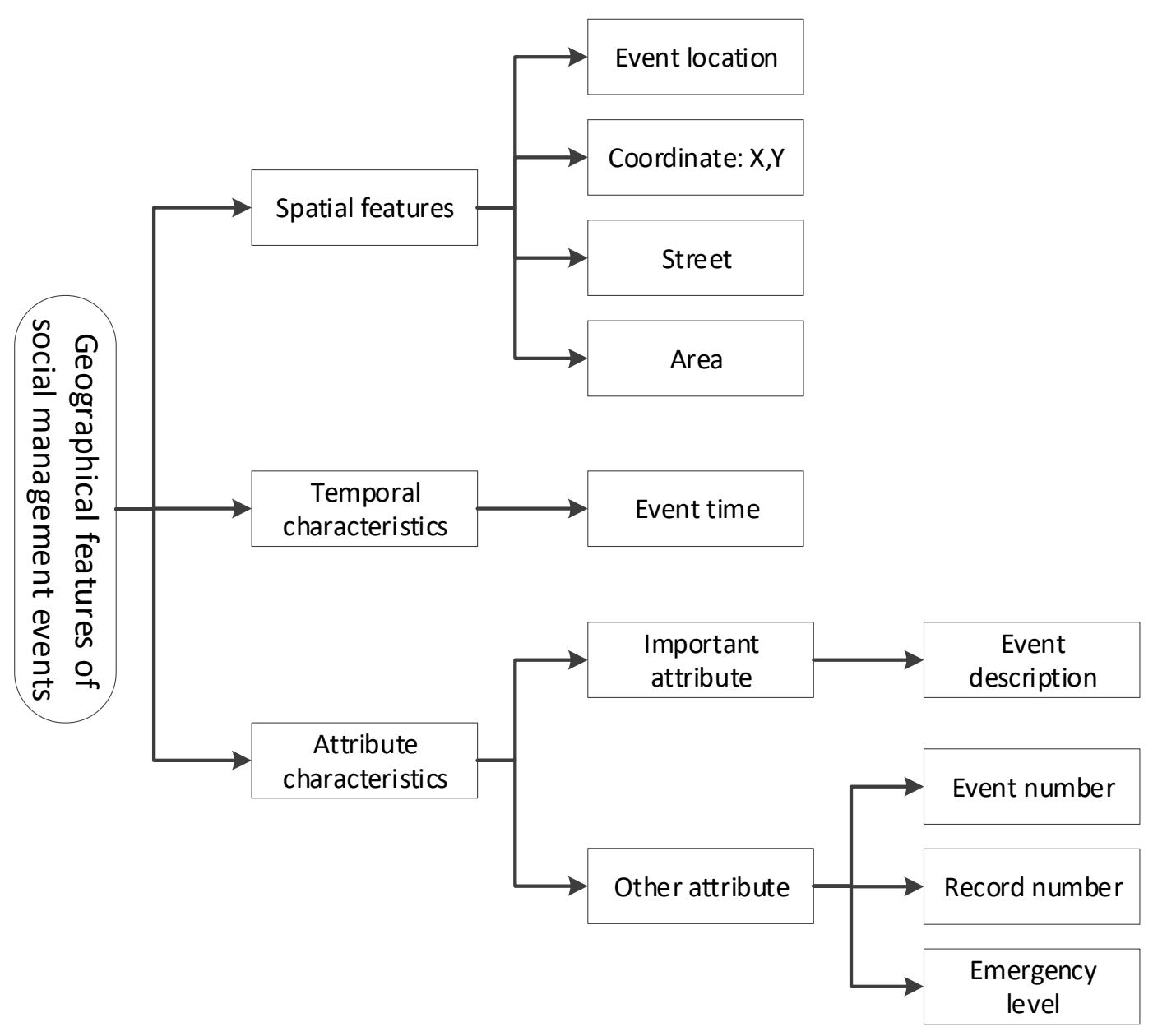

Figure 2. Geographical features of social management events.

Figure 3 shows that the quality disposal of urban social management data is based on the "event description" field, whose steps are as follows:

Step 1: Iterate through each record of the database, and check the "event description" and the spatial feature field of each event.

Step 2: If the fields are complete and without error, jump directly to (3) and process each field, according to the principle described in the previous article. If a field can be repaired, jump to (3). If it cannot be repaired, discard the record.

Step 3: Match the record with each record in the new database. If records in the new data do not repeat that record, add the record to the new database; otherwise, discard the record.

Step 4: Iterate through the original database until all records are processed.

\subsection{Information Extraction of USMEs Based on Ontology Semantic Reasoning}

We rely solely on the location and time data of urban management events, but the information that can be mined, is limited. However, a wealth of information is contained in the text fields, which describe events. This article designs its conceptual architecture diagram and ontology model by analyzing the type structure system of urban social management events. The ontology of social management events are built through the ontology-building tool. Jena is an open source program development framework, which provides a powerful semantic ontology reasoning with OWL and RDFS as ontology description language [53,54]. Thus, the Jena framework is used to design and implement the semantic reasoning and event information extraction based on the ontology. 


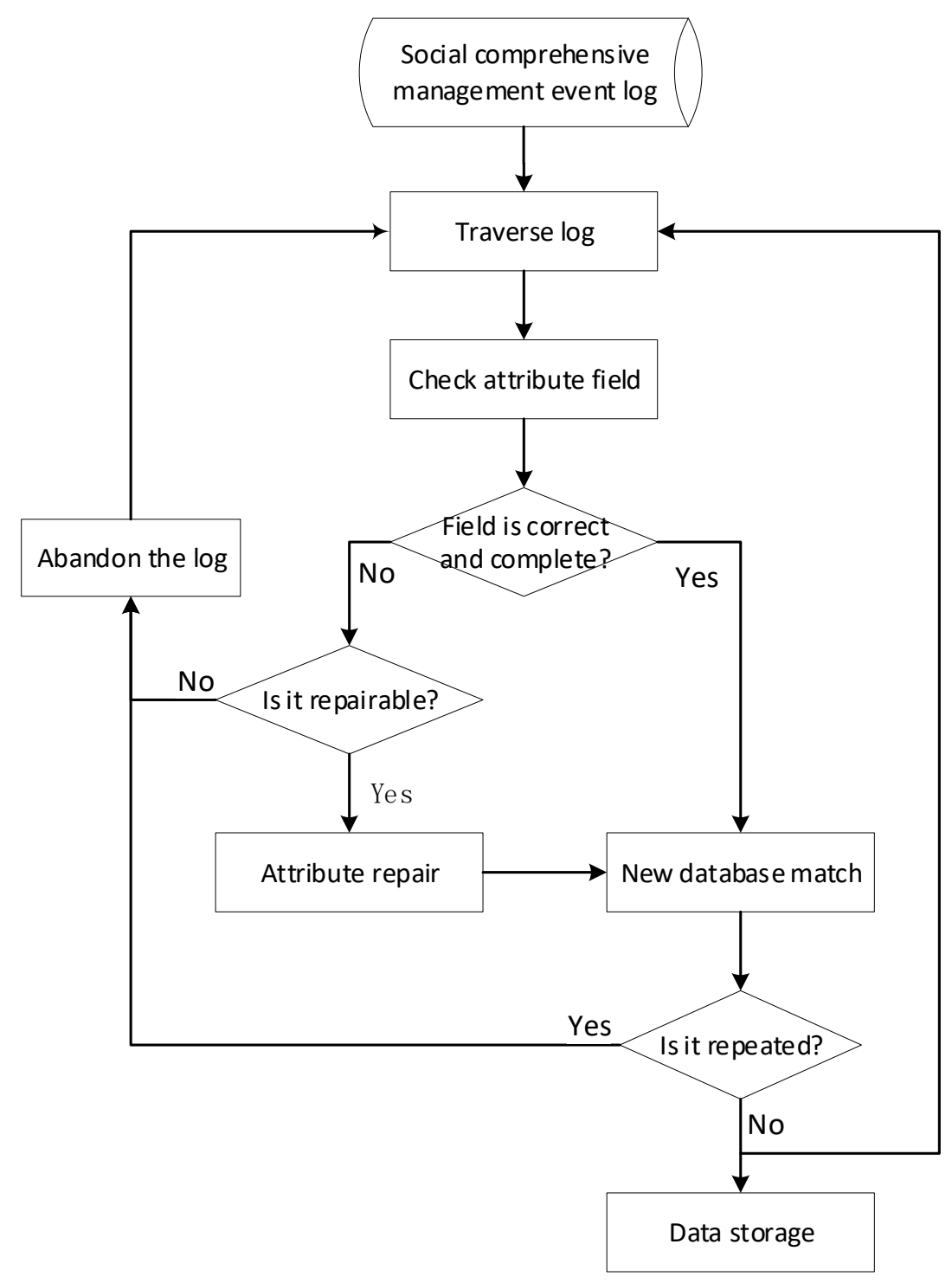

Figure 3. Quality management processes for urban social management events.

\subsubsection{Conceptual Architecture Diagram of USMEs Ontology}

The ontology conceptual system of the event type is the foundation of ontology construction. This study divides urban social management events (USMEs) by the types and their conceptual architecture of ontology types (Figure 4).

Figure 4 shows that urban social management event types can be divided into the following: population management, public security, service of livelihood, infrastructure maintenance, environmental hygiene management, urban management, and dispute resolution. Among these types, population management, public security, public service, infrastructure maintenance, and environmental hygiene management have broad categories of events, and it can be divided into many subclasses of events. Moreover, each subclass can contain a large number of entities. Given the diversity of social structure, the conflicts of disputes occur frequently. Thus, the dispute mediation events are listed separately as the focus of the event. 


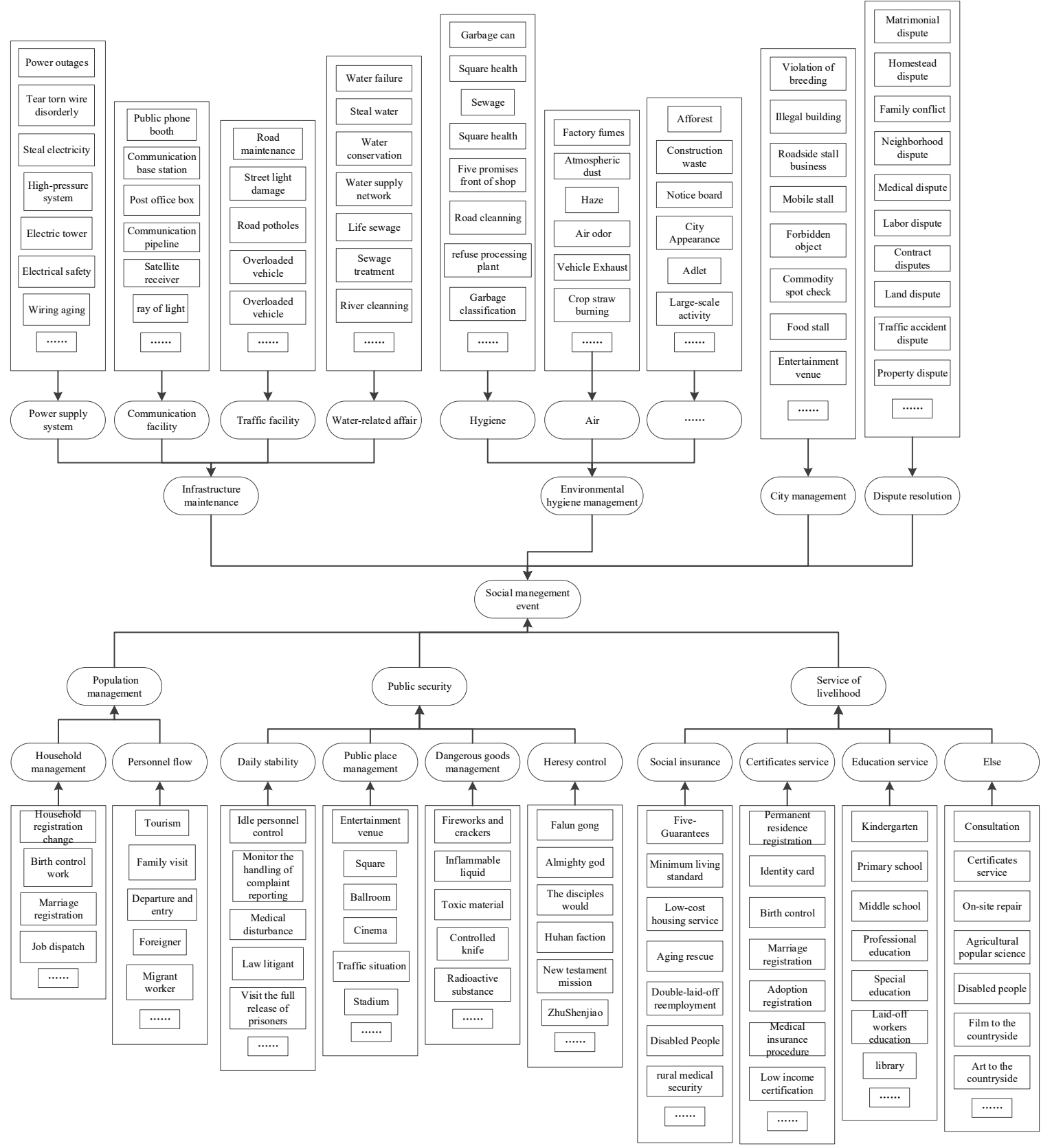

Figure 4. Conceptual Architecture Diagram of USMES.

\subsubsection{Ontology Expression and Modeling of USMEs}

According to the ontology concept model of urban social management, the present study adopts a five-element group to express the ontology. The ontology model of the five-tuple model $\left(T_{G D O}\right)$ of the urban social management event type is defined as Equation (1)):

$$
T_{G D O}=\langle T C c, T R, T P, T C s, T I\rangle,
$$

where

$T C c$ are the type concepts that represent a collection of event types;

$T R$ are the type relations that represent a relationship collection of event types between concept and concept, concept and instance, and instance and instance; 
$T P$ are the type properties that represent the relationship attribute of the event type and its data attribute, such as the relationship attribute between "complaint reporting and handling" and "daily maintenance";

$T C s$ is the type constraint that represents the constraint set of the event ontology, including the value type of the property, range, and base, such that the event coordinates cannot be outside the research area;

TI are the type individuals that represent the instances of the event type ontology, that is, specific to individual events.

According to the original language of the five-tuple event ontology, ontology modeling can be carried out for urban social variety treatment events, which include conceptual set modeling, conceptual relation modeling, and semantic relationship modeling.

This study adopts the open source ontology construction tool Protégé and introduces the idea of "incremental development" of software engineering. This study proposes a modular seven-step method ontology construction method (Figure 5), which divides the social variety into subdomains from top to bottom. Each sub-domain corresponds to a sub-body. The sub-ontology is nested with multiple sub-bodies, and the total body is pieced together from the sub-bodies of multiple modules.

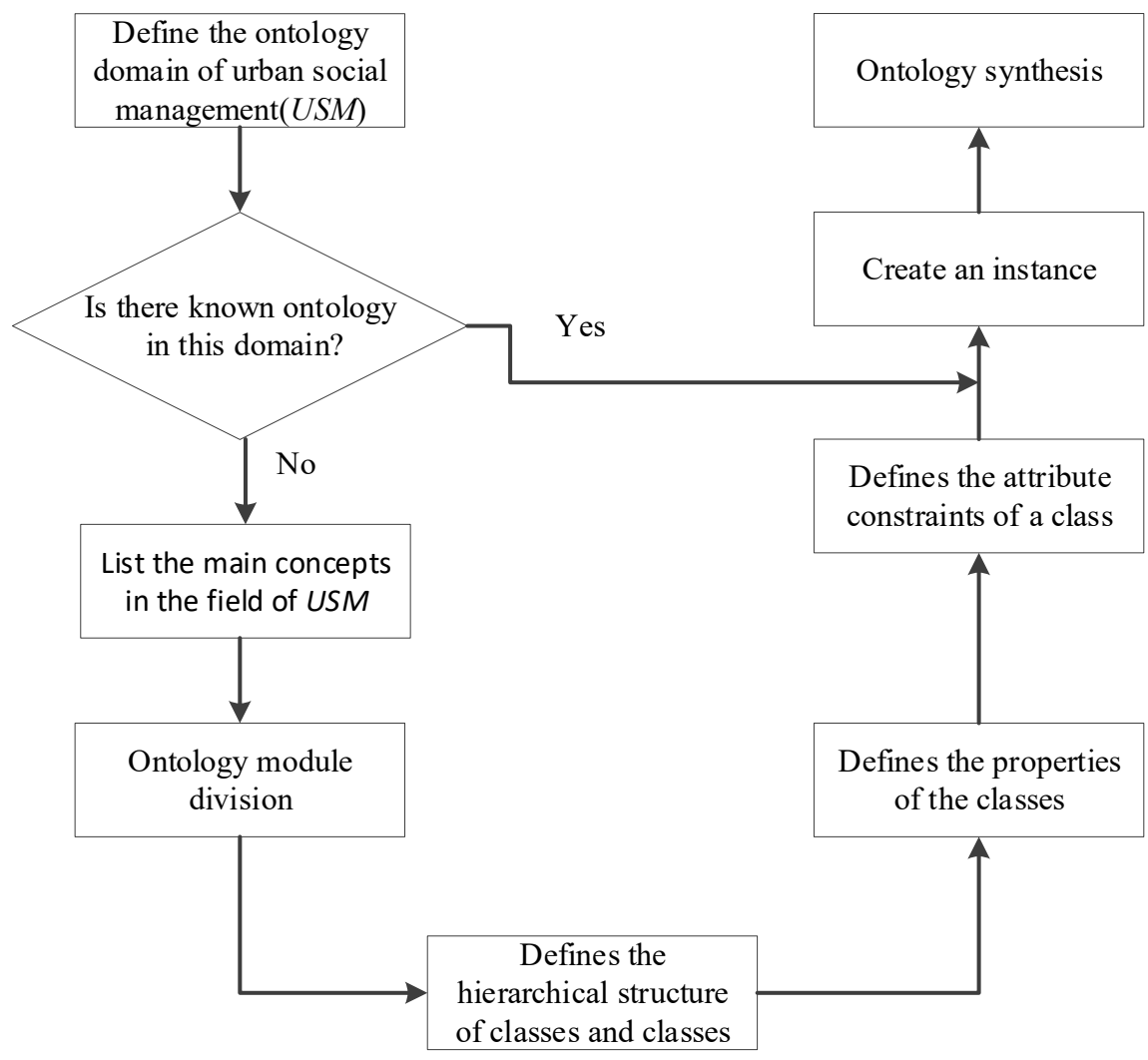

Figure 5. Construction Process of Urban Social Management Events.

As Figure 5 shows, the ontology contraction process of USME includes seven steps. Firstly, the ontology domain of USM should be defined. If the ontology in this domain existed, an instance is created based on the existent ontology for the following ontology synthesis. Otherwise, the basic elements of the ontology in USM should be constructed including classes, hierarchical structure among classes, properties of classes and attribute constraints of certain classes etc. In the ontology modeling process, ontology module division attempts to consider the decoupling between modules and divides the event and its description into multiple modules, which can be combined into sets of ontology, such as "site ontology" (place name description ontology and coordinate ontology). The attributes of 
the classes are mainly divided into two categories: Data attributes and object attributes, which mainly include the description attributes of the concept of the social management event and the relationship between concepts and concepts. Attribute constraints are mainly limited to conceptual attributes, such as the range of values and date accuracy. The open source ontology software Protégé [53-57] with OWL 2 is presented for the ontology construction for the variety ontology creation of the urban social treatment event.

\subsubsection{Ontology Semantic Reasoning of USMEs}

The technical framework of ontology semantic reasoning for USMEs is shown as Figure 6.

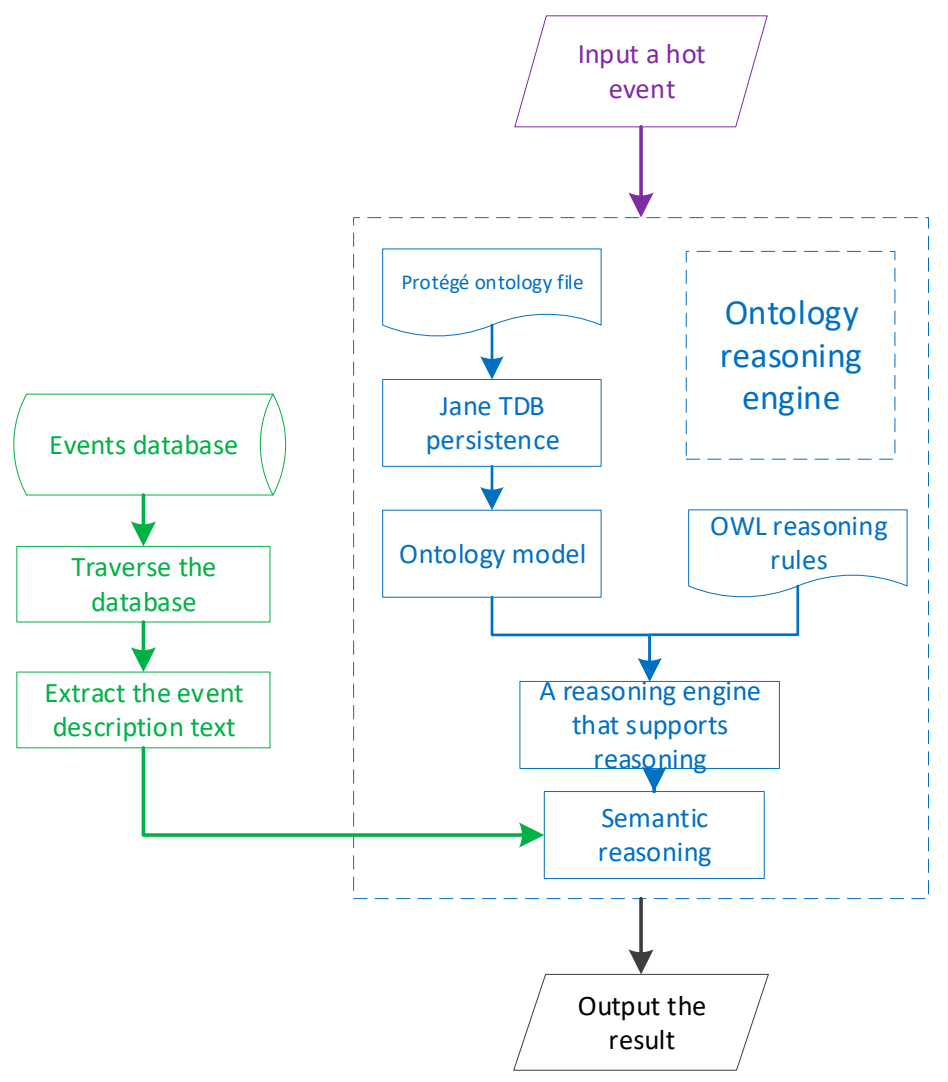

Figure 6. Flowchart of ontology reasoning of USMEs.

Figure 6 shows that ontology semantic reasoning is based on the Jane framework and Protégé software, which provides rich conceptual relationships, such as "functional", "Inverse Functional", "Inverse of", "Transitive, Symmetric", "Reflexive" and "Irreflexive" [53-57]. The inference rules are based on the reasoning function of "Transitive, Symmetric and Irreflexive" to describe the relationship between social management events. The inference system first reads and parses the ontology files of Protégé and analyzes the classes, instances, and various attributes of the ontology model by using Jena TDB [58] to persist the ontology file, combining the ontology relationship of OWL 2 description, and constructing an ontology inference engine that supports semantic reasoning. The extraction of a hot event is taken as an example as follows: A hot event, such as "conflict dispute" is entered, the database is traversed, and the description text of the event is extracted. The semantic relation is presented for the ontology reasoning to extract events from the source data with the support of the ontology inference engine and Protégé software, the hot events are matched with each data to obtain all the matching results. The key algorithm of the semantic reasoning of USMEs based on the Jena framework is shown in Algorithm 1. 


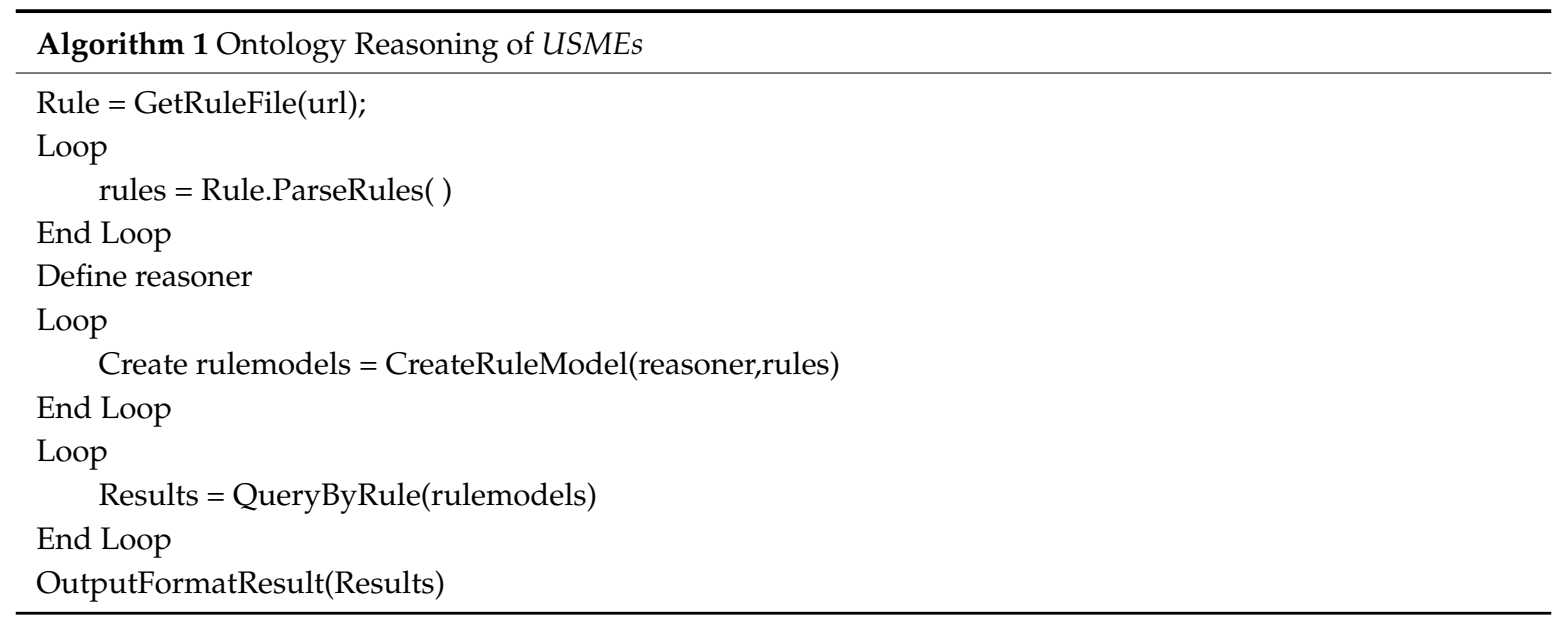

\subsection{Spatio-Temporal Data Mining with USMEs}

A relationship is observed between the spatial distributions of the comprehensive management of social events. For example, social security may not be good in areas where disputes are frequent, and elderly aid events are relatively concentrated in poor or rural areas. This study explores the temporal and spatial patterns of urban social management events from three aspects of "event-place," "event-event," spatial relevance, and "event-event" time relevance.

\subsection{1. "Event-Place" Spatial Correlation}

We present in this paper the clustering center method and the direct distance method to explore the correlation between the events and the designated locations.

\section{(1) Cluster center method}

The basic idea of clustering center method is as follows:

Firstly, the point density analysis method obtained a plurality clustering center of the event. The Kernel density estimation $[59,60]$ is presented for the point density analysis to obtain the clustering center. The point density analysis of one event is as Figure 7 shows.

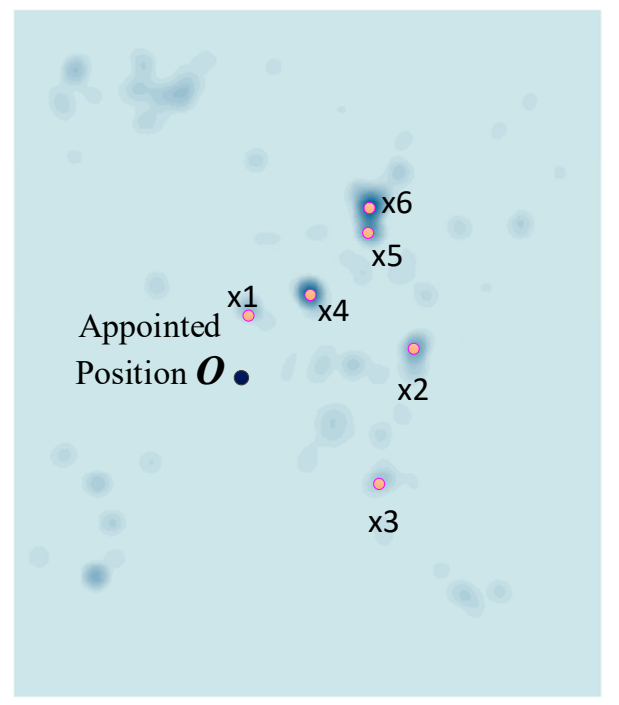

Figure 7. "Event-Place" correlation analysis based on Cluster Center Method.

As Figure 7 shows, the event has six cluster centers within the range $O$. 
Secondly, calculate the sum of the weighted distance reciprocal between the cluster center and the specified location. In Figure 7, the weighted distance reciprocal of the place $O$ to the clustering center $\left(X_{1}, X_{2}, X_{3}, X_{4}, X_{5}, X_{6}\right)$ are added up.

Thirdly, the average weighted distance reciprocal is taken as the clustering center spatial correlation discriminant factor $h$, as Equation (2):

$$
\hbar=\varphi \sum_{i=1}^{n} \frac{\mu_{i}}{D_{i}}
$$

where $n$ is the number of cluster centers, $D_{i}$ is the distance of $O$ to the cluster center $X_{i}, \mu_{i}$ is the weight of $X_{i}$, which is determined by the density factor. $\varphi$ is the correction factor. The discriminant factor increases, the correlation is stronger.

(2) Direct distance clustering method

Different from the cluster center method, the direct distance clustering method omits the event clustering, which takes the distance from the event to the site as the direct factor. The basic idea is as follows: First, set a suitable location for the center of the screen space, screening at all points in space; then, calculate the distance to draw distance, as the discriminant factor correlation. As shown in Figure 8.

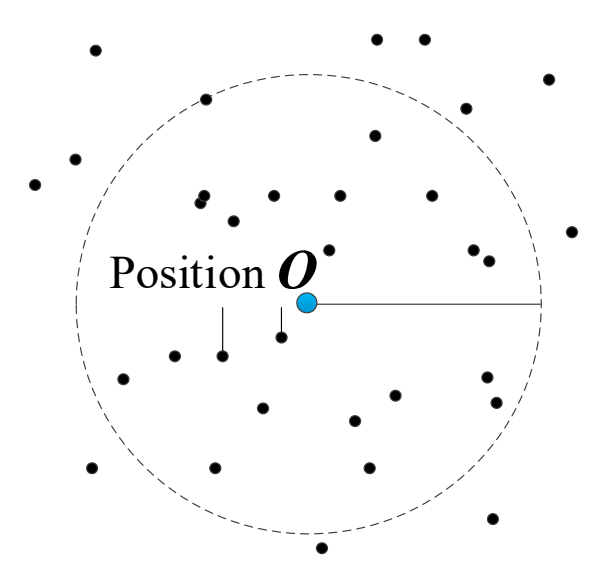

Figure 8. "Event-Place" correlation analysis based on Direct Distance Clustering Method.

The discriminant factor of the direct distance clustering method $h$ is calculated by Equation (3):

$$
\hbar=\sum_{i=1}^{n} \frac{\varphi}{D_{i}}
$$

where $n$ is the number of events in the filter space, $D_{i}$ is the distance from the $i$ th event to the location $O$, and $\varphi$ is the correction factor.

\subsection{2. "Event-Event" Spatial Correlation}

"Event-event" spatial correlation can be used to explore the inducement and accompanying relationships of events from the perspective of spatial distribution. For example, air pollution and sewage discharge have some kind of association, most of them are caused by factory sewage. By comparing the correlation between floating population events and social security incidents, we can explore the impact of population mobility on social security. The idea of exploring the spatial correlation of "event-event" space is shown in Figure 9. 


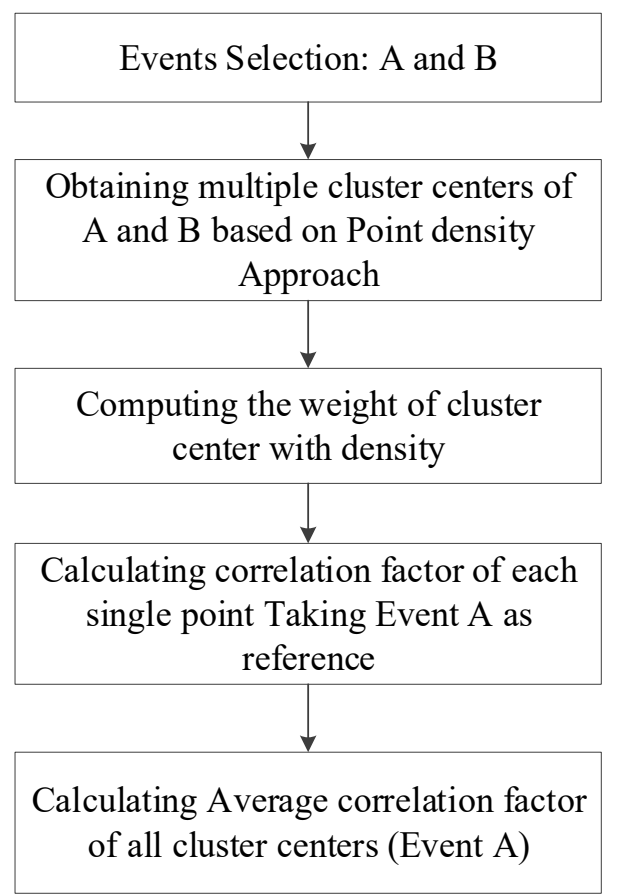

Figure 9. Flowchart of the spatial correlation exploring between "event-event".

Figure 9 shows that the "event-event" spatial correlation analysis algorithm includes the following steps:

Step 1: Two kinds of events involved in the evaluation are clustered by the density method to generate the clustering centers of two kinds of events.

Step 2: Each cluster center is assigned a weight that matches the density value according to the density factor. The higher the density factor is, the greater the weight is.

Step 3: The clustering centers of another event are traversed on the basis of one kind of event. The sum of the mean weighted distance reciprocal in the neighborhood space of the datum cluster center is calculated with the specific size of the neighborhood space.

Step 4: The average weighted distance by the reciprocal sum of all clustering centers is accumulated, and the average value is calculated as a correlation measurement factor (Equation (4)).

$$
\hbar=\frac{\varphi}{n} \sum_{i=1}^{n}\left[\frac{1}{m_{i}} \sum_{j=1}^{m_{i}} \frac{\left(\mu_{i}^{A}+\mu_{j}^{B}\right)}{D_{i, j}}\right],
$$

where $n$ is the clustering center number of events $A, m_{i}$ is the number of $i$ th clustering center in $A$ events, which are in the neighborhood of the clustering center in events $B, D_{i j}$ is the event clustering center distance between $i$ th the cluster center of events $A$ and $j$ th the clustering center of events $B, \mu_{i}^{A}$ is the weight of $i$ th clustering center of events $A$, and $\mu_{i}^{B}$ is the weight of $j$ th clustering center of events $B$. $\varphi$ is the correction factor.

Figure 10 gives an example of "event-event" spatial correlation analysis. 


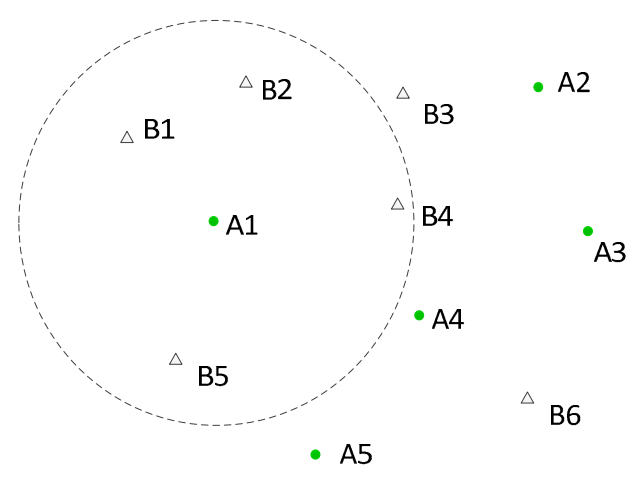

Figure 10. Example of exploring the spatial correlation between "event-event".

Figure 10 shows that event $A$ is used as the basis. Event $B$ is the object to be traversed. At first, $A 1$ is taken as the clustering center; thus, all event B's in the neighborhood space of $A 1$ are traversed to calculate the correlation factor as the presented algorithm. The calculation for $A 2, A 3, A 4, A 5$, and all $A^{\prime}$ 's are transversed, until all event $A^{\prime}$ 's are traversed.

\subsection{3. "Event-Event" Time Correlation Analysis}

The time correlation between events is to explore the succession, concomitant, and incentive relationship of events from the perspective of time distribution. The time correlation between events depends on spatial correlation. Only if the events have spatial correlation, is the time correlation of events meaningful. For example, it is assumed that there is a periodic correlation between the sewage discharge events in Wuhan and the environmental sanitation events in Qingdao, but this relevance has no significance, because Wuhan and Qingdao are too far apart in space, and the sewage discharge in Wuhan has little impact on the environmental sanitation of Qingdao.

A flowchart to explore the time correlation between events is shown in Figure 11.

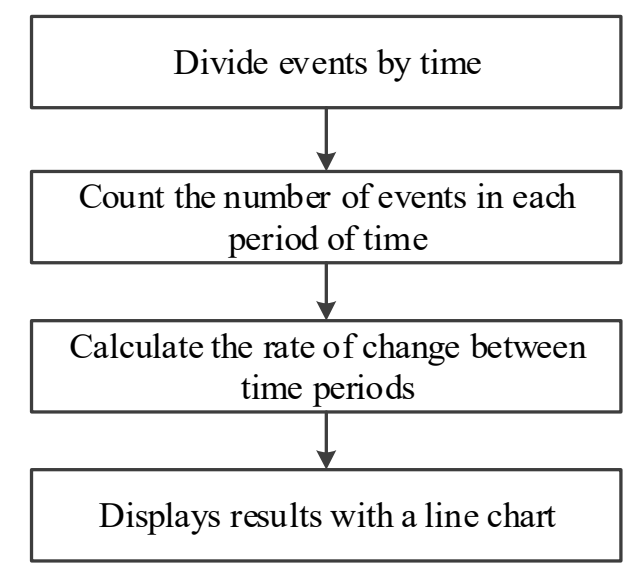

Figure 11. Flowchart of "Event-Event" Time Correlation Analysis.

Figure 11 shows the following. First, according to a certain time interval, such as the month or week, the number of events is counted within each time period. Second, the increase in the number of events is used as a measure of standards to calculate the event gain in the adjacent period. Finally, the change between the two events and visualization is compared. The time correlation between the events can be measured.

In the "Event-Event" time correlation exploring analysis, the calculation scheme of time interval and increase is an important factor that affects new exploration. The event interval must be chosen 
according to the periodic nature of the event itself. An increase in events over time can be calculated by the quantity of the current unit of time and the number of units of the previous time, as the standard of gain. You can also choose the sum of the quantities of the previous two or three time units as the uptrend indicator. Considering the possibility that the number of events is zero for some time period, it is appropriate to select the sum of the events in the first two or three time periods as divisors.

\section{Results}

\subsection{Dataset}

The experimental data is the USMEs of Jiaonan city and Huangdao District in Qingdao City, Shandong Province, China. The time spans are from 22 August 2014 to 8 February 2017. There are 2,162,302 events data in total (Figure 12). These USMEs are from Qingdao City Management System, an actual running system in the government of Jiaonan City and Huangdao Distrcit.

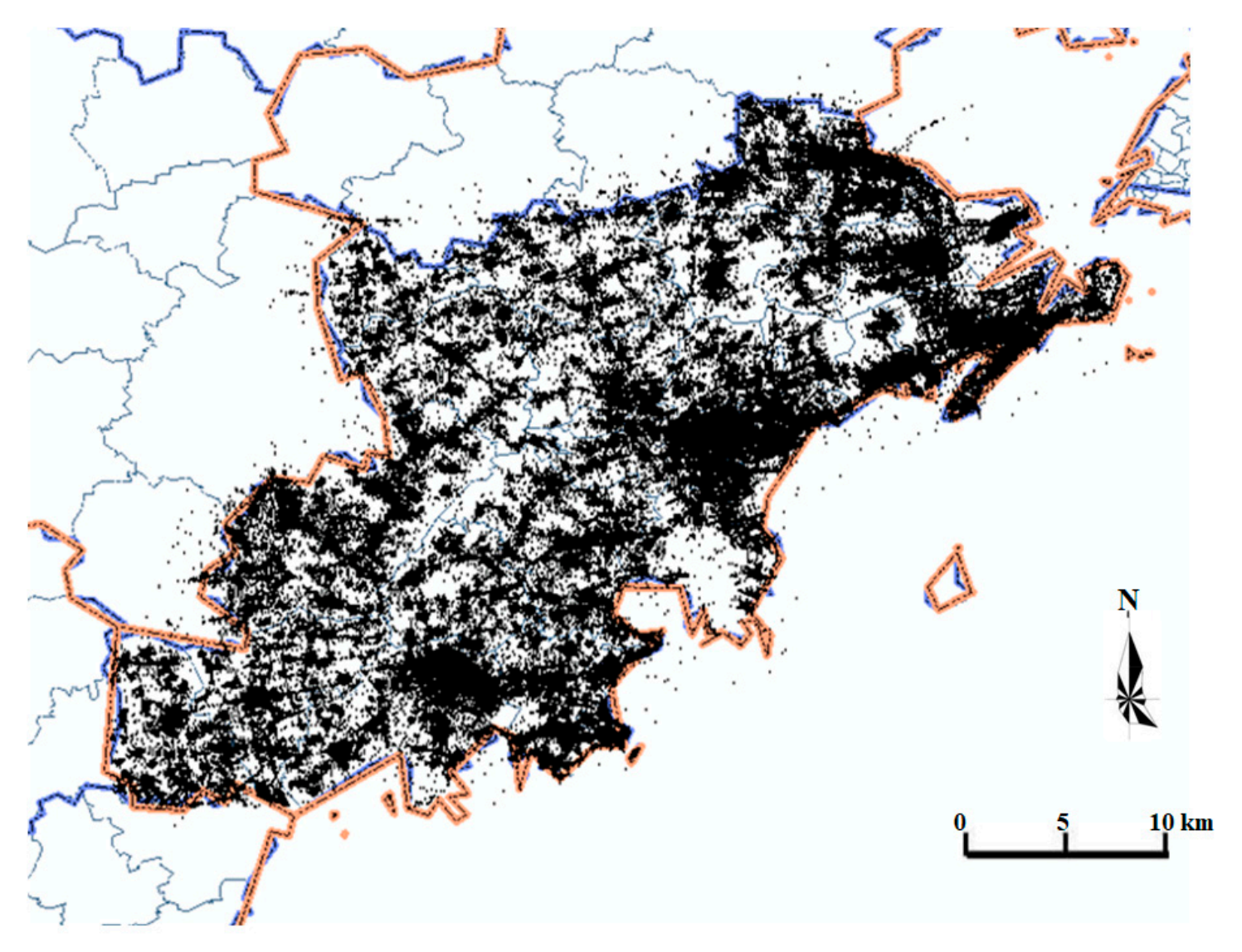

Figure 12. Dataset of USMEs for the experiment.

Figure 12 shows that the events are aggregated and scattered in the spatial distribution. Dispersion reflected in the data is full of the entire research space. Aggregation is reflected in the data within the scope in different scales of space gathered.

Figure 13 is the satellite remote sensing images (from IKNOS with resolution of $1 \mathrm{~m}$ ) in the experiment region. 


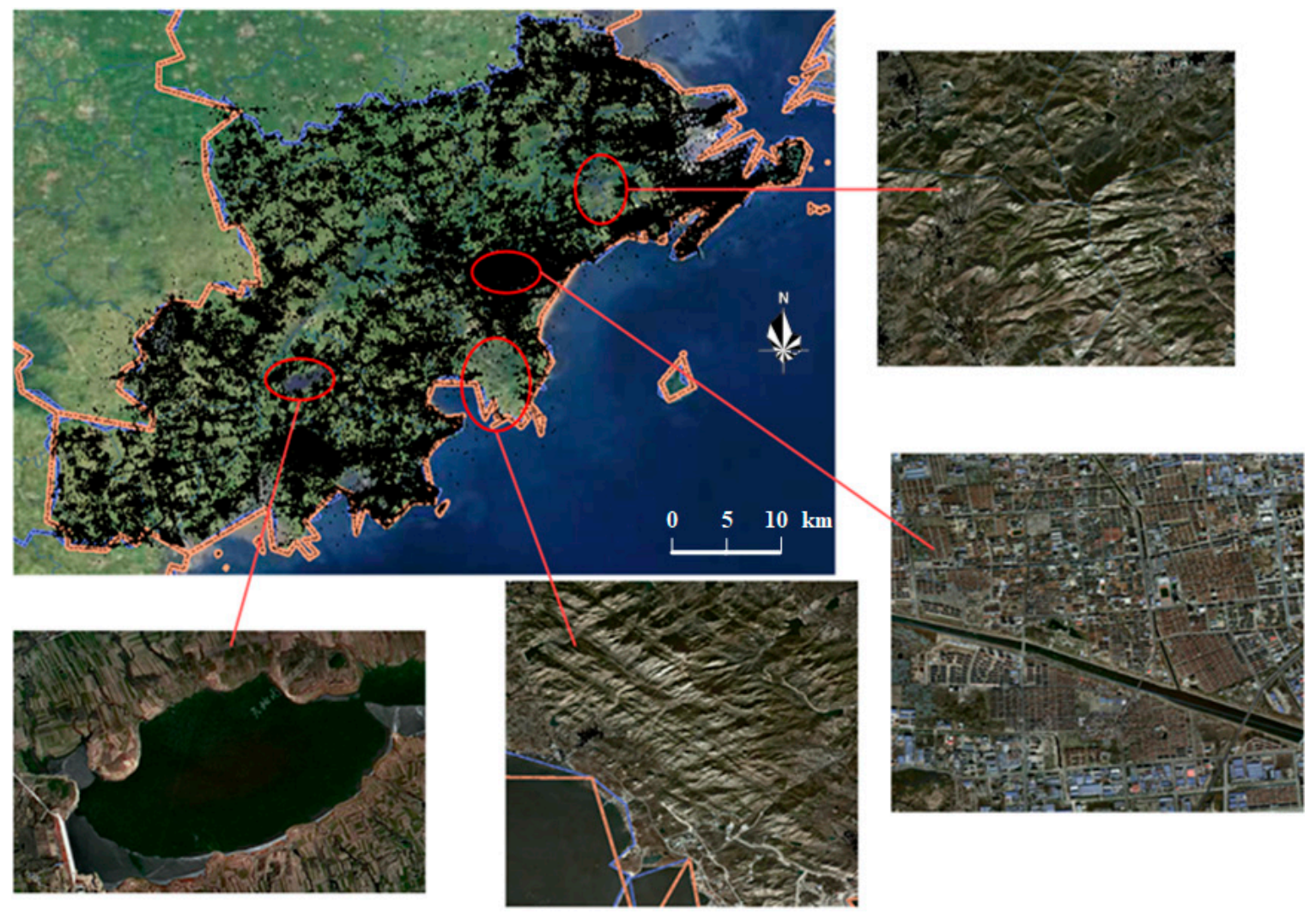

Figure 13. Satellite remote sensing images in the experiment region.

Figure 13 shows the events of large-scale aggregation of the area for the city and the small-scale gathering place for rural areas. The experimental area of Jiaonan City and Huangdao District is a hilly-based region. The territory of large and small mountains of human activities are divided into a large number of scattered large and small areas. The whole study area has several highly populated urban areas and a large number of scattered rural areas. This regional division led to a pluralistic study area of society with both urban and rural elements. The types of social comprehensive management events are relatively rich and representative.

\subsection{Hot Events Extraction}

This study includes urban and rural study areas. The elements of social management are more highly complicated than modern cities. The proposed ontology-based semantic reasoning method is used to extract disputes of hot events and spatial statistics in the district's grid, and statistical results are shown using a boxplot (Box Whisker Plot) and scatter diagram (Scatter Plot) (Figure 14).

Figure 14 shows that, in most of the district, the disputes events are not frequent and are below the average. However, in the Changjiang East Road Management Zone, Wanggezhuang Management Zone, and Paifang Street Management Zone, the activities frequency of the three management zones are excessively dense, which are dozens of times of the average and significantly higher than the other areas. The data shows that the number of Wanggezhuang Management Zone is 27 times of the average. The number of the Changjiang East Road Management Zone is 22 times of the average. The number of Paifang Street Management Zone is 18 times of the average. Therefore, dispute events have clustering characteristics in spatial distribution. In most of the district, dispute events are not active. In individual areas, disputes are slightly hot events that frequently occur in the Changjiang East Road Management Zone, Wanggezhuang Management Zone, and Paifang Street Management Zone, which have extremely frequent dispute events. 


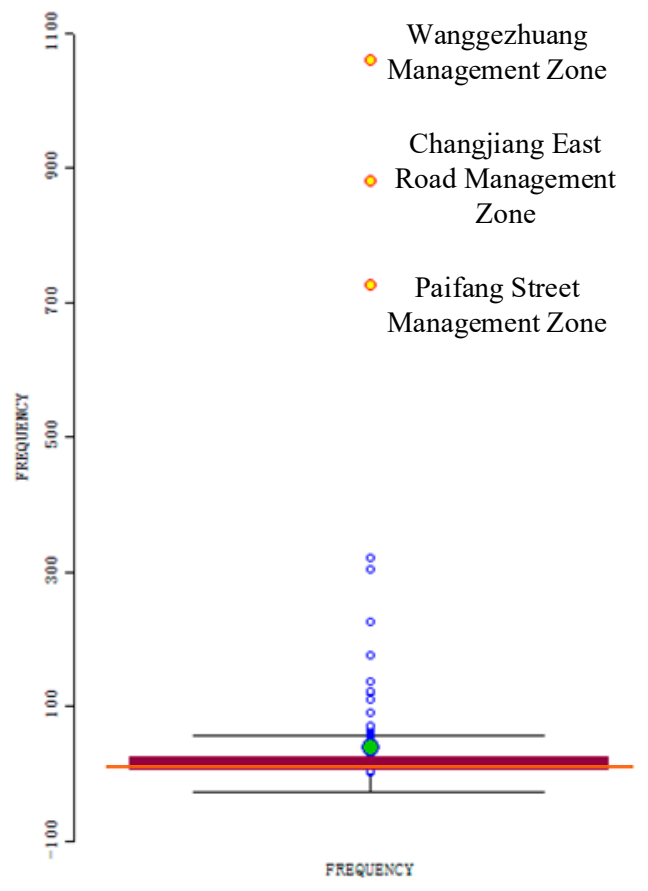

(a) Box Whishker Plot

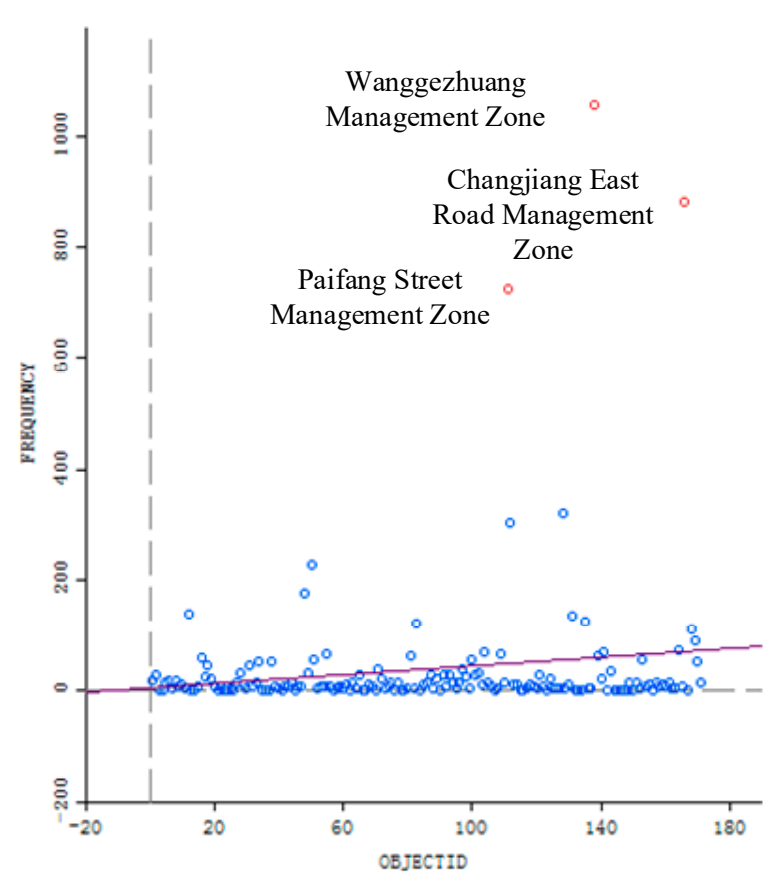

(b) Scatter Plot

Figure 14. Spatial distribution of "Dispute" Hot Events.

Moreover, the number of monthly conflicts and disputes are counted by month, and the result is shown in Figure 15.

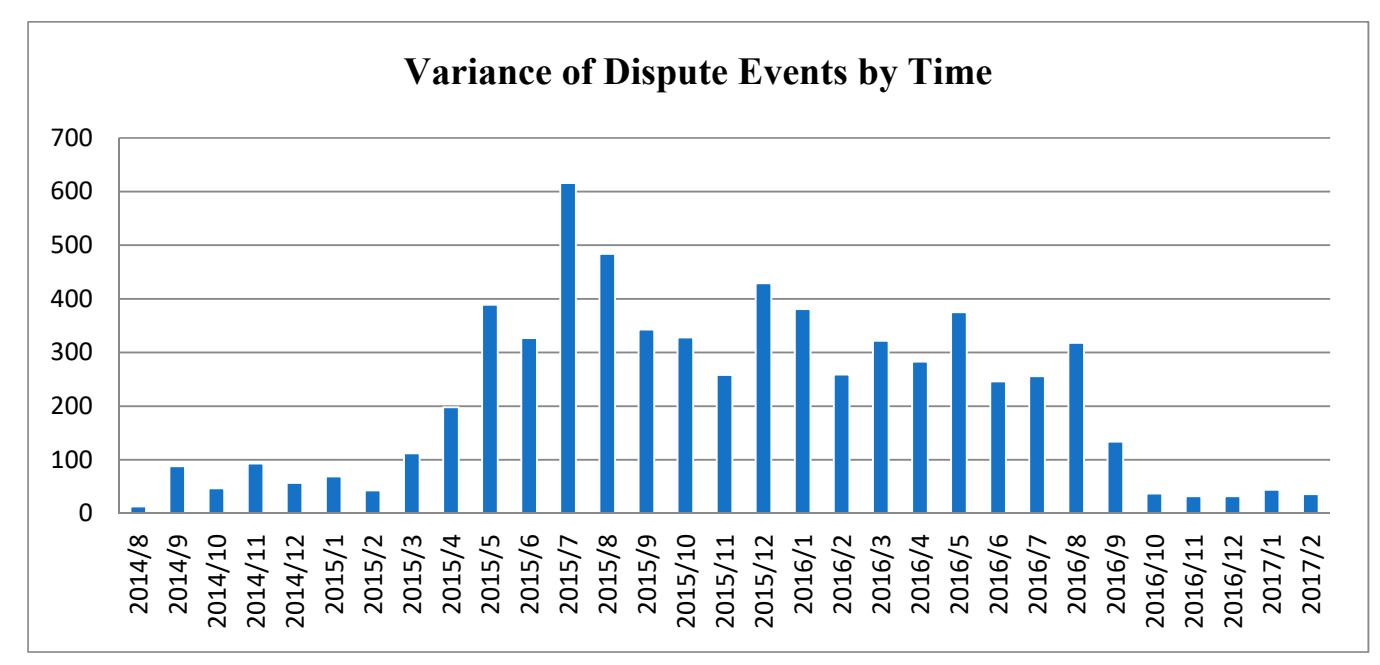

Figure 15. Time series characteristics of "dispute" events.

Figure 15 shows that, although the "dispute" events did not show cyclical characteristics, the "dispute" events in the distribution of time are not uniform, and the difference is large. April 2015 to August 2016 is a frequent time period for contradictions and disputes.

Figure 16 gives the thermodynamic diagram of the spatial focusing characteristic of "dispute" events, and Figure 17 is the spatial distribution change of "dispute" events in different years. 


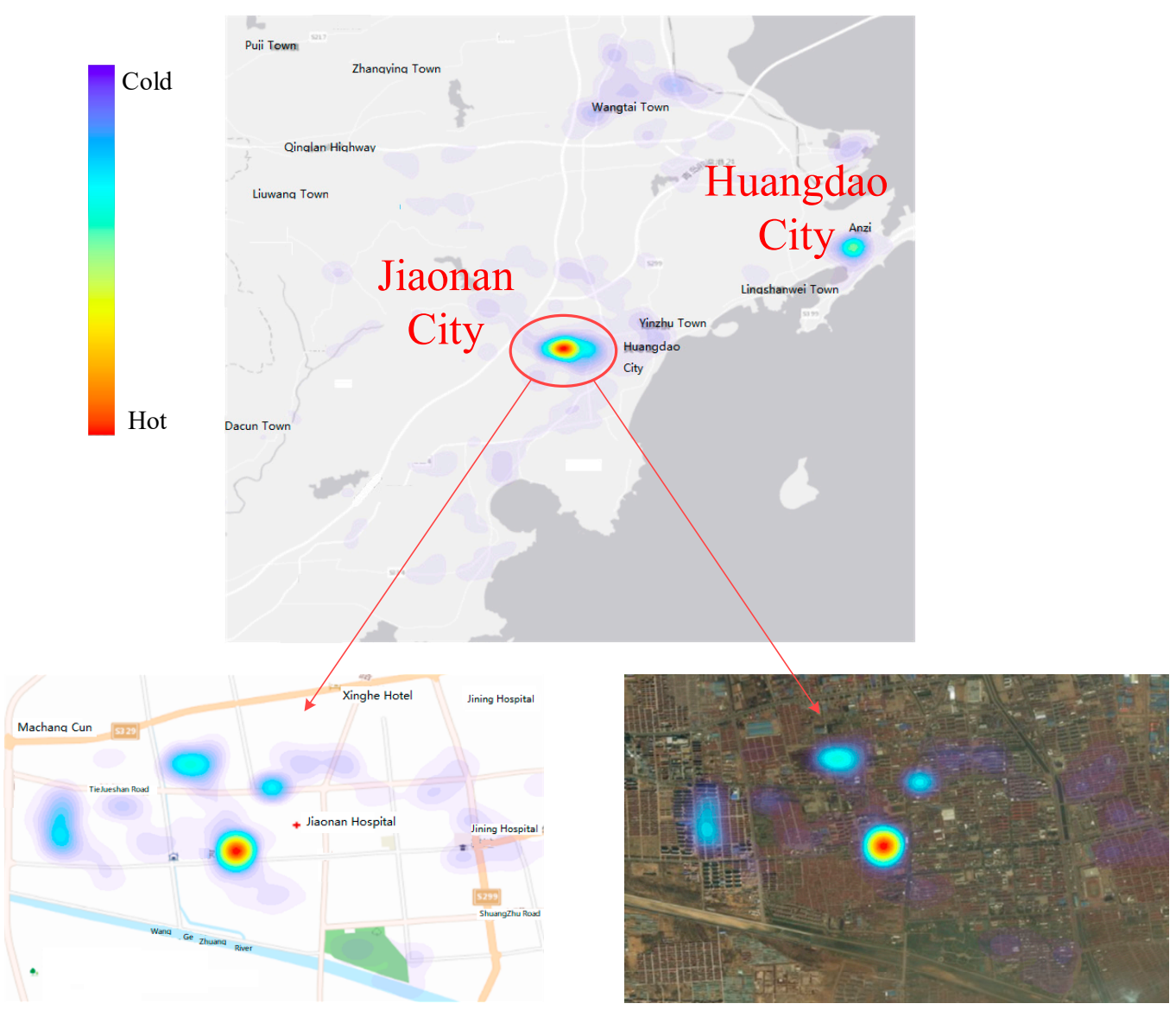

Figure 16. Thermodynamic diagram of the spatial focusing characteristic of "dispute" events.

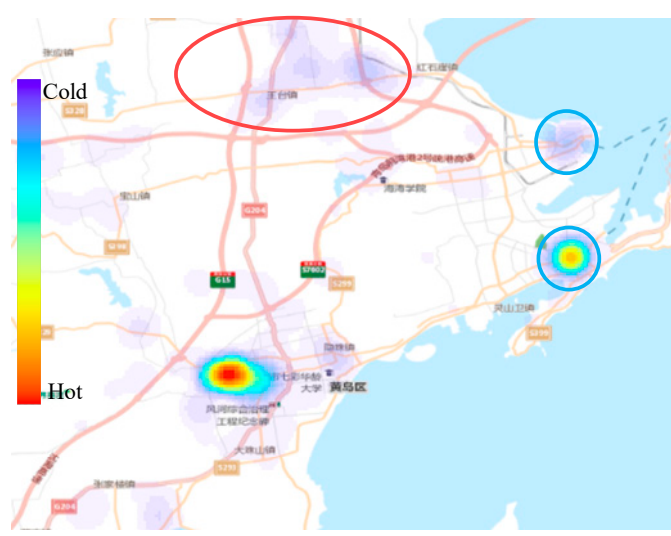

(a) Spatial distribution of “dispute” events (2015)

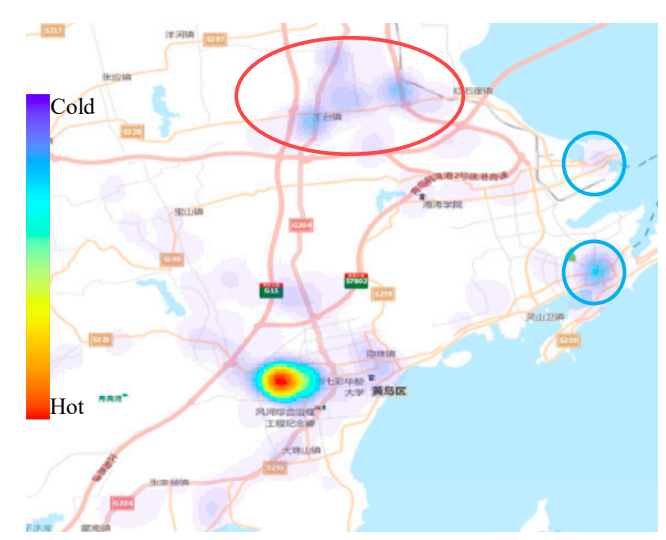

(b) Spatial distribution of “dispute” events (2016)

Figure 17. Changes of "dispute" events in different years.

Figures 16 and 17 show one large gathering area and one small gathering area in the study area of "dispute" events, which are the main urban areas of Jiaonan City and Huangdao City. Jiaonan City has one large and three small gathering areas, which are in the neighborhood of Wanggezhuang Management Zone. The "dispute" events have the distribution characteristics of gathering in the main urban areas. The activity is not high although other rural areas have some "dispute" events. Thus, the main manpower of the city's administration should be arranged in the main city, especially the main city of Jiaonan City and the neighborhood of Wanggezhuang Management Zone. 


\subsection{Spatial Distribution Correlations Analysis Result of "Events-Places"}

"Petition" events are used as examples for the spatial distribution correlations analysis of "events-places." Figure 18 gives the result of the spatial distribution correlations analysis with the proposed cluster center method.

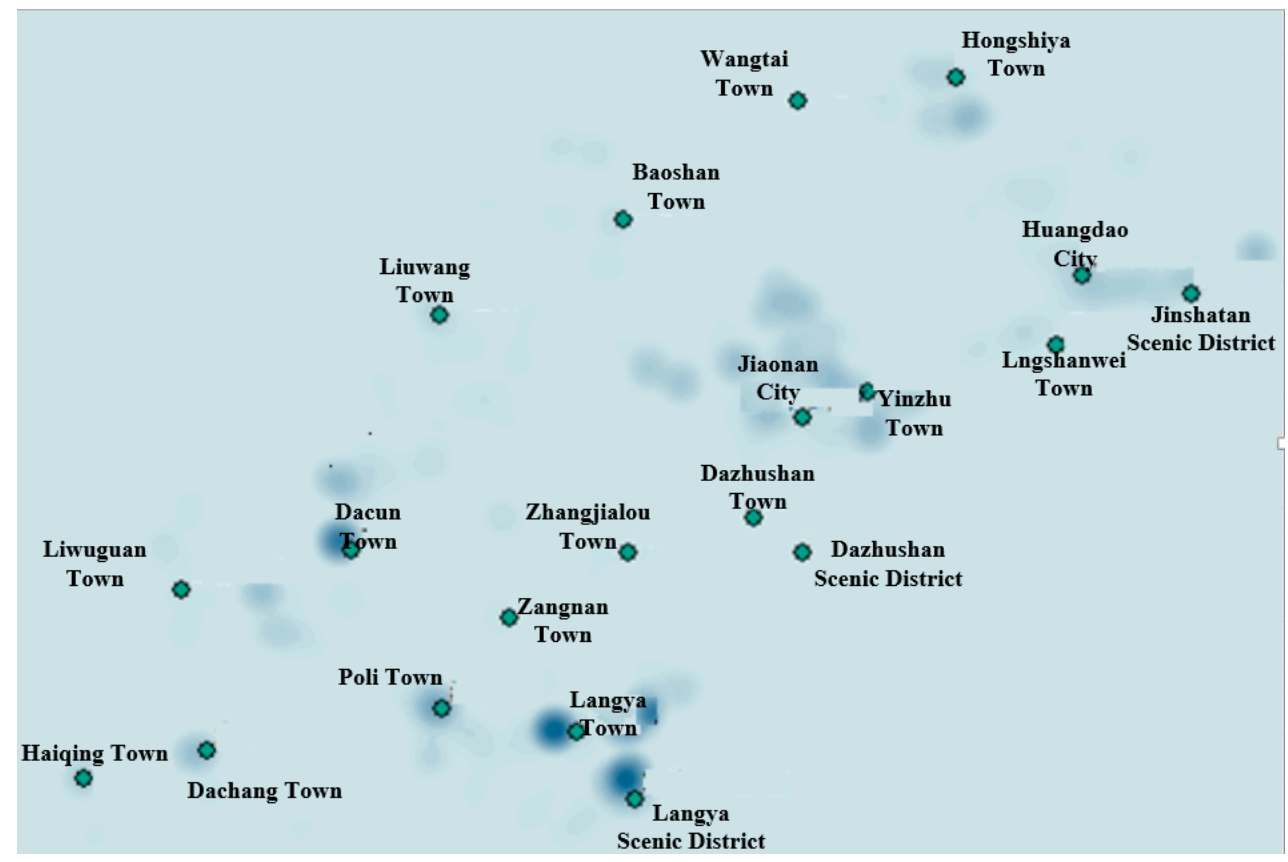

Figure 18. Spatial distribution correlations analysis of "Petition" events from the aspect of "events-places".

Figure 18 shows that the spatial correlations of Langya Terrace, Langya town, big town, and some other places with events of visiting are preliminarily high. Table 1 gives correlation factors of "Petition" events in all places.

Table 1. Correlation factors of "Petition" events in all places.

\begin{tabular}{cccccc}
\hline Place & $\begin{array}{c}\text { Correlation } \\
\text { Factor }\end{array}$ & Place & $\begin{array}{c}\text { Correlation } \\
\text { Factor }\end{array}$ & Place & $\begin{array}{c}\text { Correlation } \\
\text { Factor }\end{array}$ \\
\hline Langya Town & 102.135 & Liuwang Town & 0.073 & Baoshan Town & 0.124 \\
Langya Scenic District & 98.217 & Zhangjialou Town & 0.215 & Wangtai Town & 0.211 \\
Poli Town & 51.284 & Zangnan Town & 0.496 & Huangdao City & 8.612 \\
Dachang Town & 10.341 & Dazhushan Town & 0.408 & Lingshan Town & 2.4 \\
Haiqing Town & 0.956 & Dazhushan Scenic District & 0.384 & Hongshiya Town & 3.173 \\
Dacun Town & 44.277 & Jiaonan City & 5.006 & Jinshatan Scenic District & 4.626 \\
Liwuguan Town & 1.757 & Yinzhu Town & 24.472 & & \\
\hline
\end{tabular}

Table 1 and Figure 18 show that "Petition" events in two places have super spatial distribute correlations: Langya Town and the Scenic District. Boli Town and Dacun Town have strong relevance of spatial distribution, while the relevance of other places is weak. After field investigation, the reasons of "Petition" are similar in these places, such as house demolition, industrial disputes, and life infrastructures destroyed for a long time. Therefore, the suggestion to the city's administration is to solve these kinds of problems early in those places to reduce events of "Petition."

\subsection{Spatial Distribution Correlations Analysis Result of "Events-Events"}

"Dispute" events and "Fight" events are used as examples of the spatial distribution correlations analysis of "events-places" from the aspects of spatial and temporal distribution correlations. 
(1) Spatial distribute correlations

Spatial clustering is presented separately for "Dispute" and "Fight" events. The strength of the clustering center is taken as the weight. High weight has high point density (Figure 19).

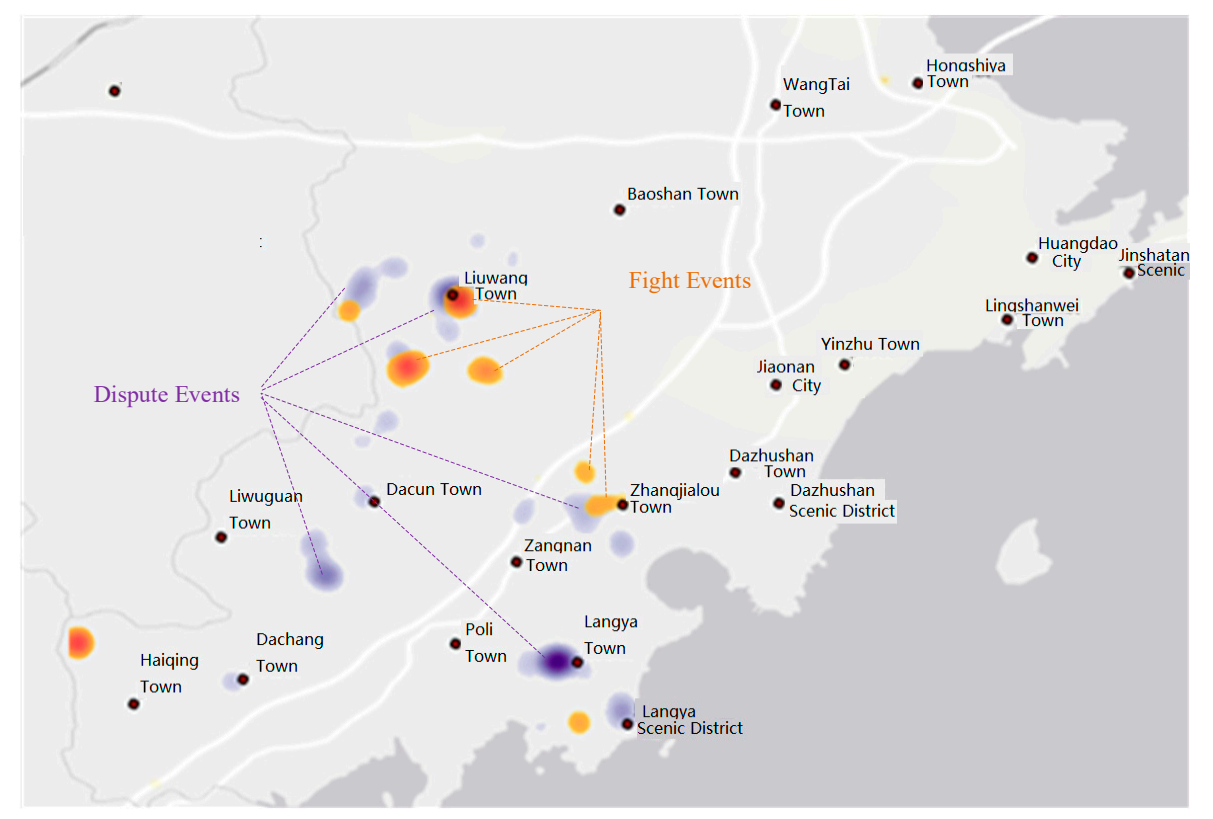

Figure 19. Distribution of data of dispute contradiction and events of fight by spatial clustering.

Figure 19 shows that the "Dispute" and "Fight" events in Liuwang have strong spatial distribution relevance. Most of the fights are caused by common contradictory disputes in this region after field investigation. Thus, the "Dispute" and "Fight" events have strong relevance.

(2) Temporal distribution correlations

Two months is the time interval for statistics. The number and variance of "dispute" and "fight" events every 2 months are shown in Table 2.

Table 2. Number and variance of "dispute" events and "fight" events every two months.

\begin{tabular}{ccccc}
\hline \multirow{2}{*}{ Time } & \multicolumn{2}{c}{ Dispute Events } & \multicolumn{2}{c}{ Fight Events } \\
\cline { 2 - 5 } & Number & Variance Ratio & Number & Variance Ratio \\
\hline $2014 / 8$ & 3680 & 0.096 & 140 & 0.149 \\
$2014 / 10$ & 4010 & -0.793 & 160 & -0.625 \\
$2014 / 12$ & 830 & 1.880 & 60 & -0.330 \\
$2015 / 2$ & 2390 & 4.272 & 40 & 4.000 \\
$2015 / 4$ & 12,600 & 1.219 & 200 & 2.250 \\
$2015 / 6$ & 27,960 & -0.353 & 650 & -0.462 \\
$2015 / 8$ & 18,080 & 0.386 & 350 & 0.200 \\
$2015 / 10$ & 25,060 & 1.159 & 420 & 0.786 \\
$2015 / 12$ & 54,100 & -0.168 & 750 & -0.080 \\
$2016 / 2$ & 44,990 & -0.022 & 690 & -0.174 \\
$2016 / 4$ & 43,990 & -0.046 & 570 & -0.246 \\
$2016 / 6$ & 41,980 & -0.020 & 430 & -0.372 \\
$2016 / 8$ & 41,160 & -0.122 & 270 & 0.000 \\
$2016 / 10$ & 36,140 & -0.290 & 270 & -0.519 \\
$2016 / 12$ & 25,660 & & 130 & \\
\hline
\end{tabular}


Figure 20 further gives the visualization result of the variance ratio of "dispute" and "fight" events for every two months from August 2014 to December 2016.

\section{Variance Ratio of Dispute-Fight Events}

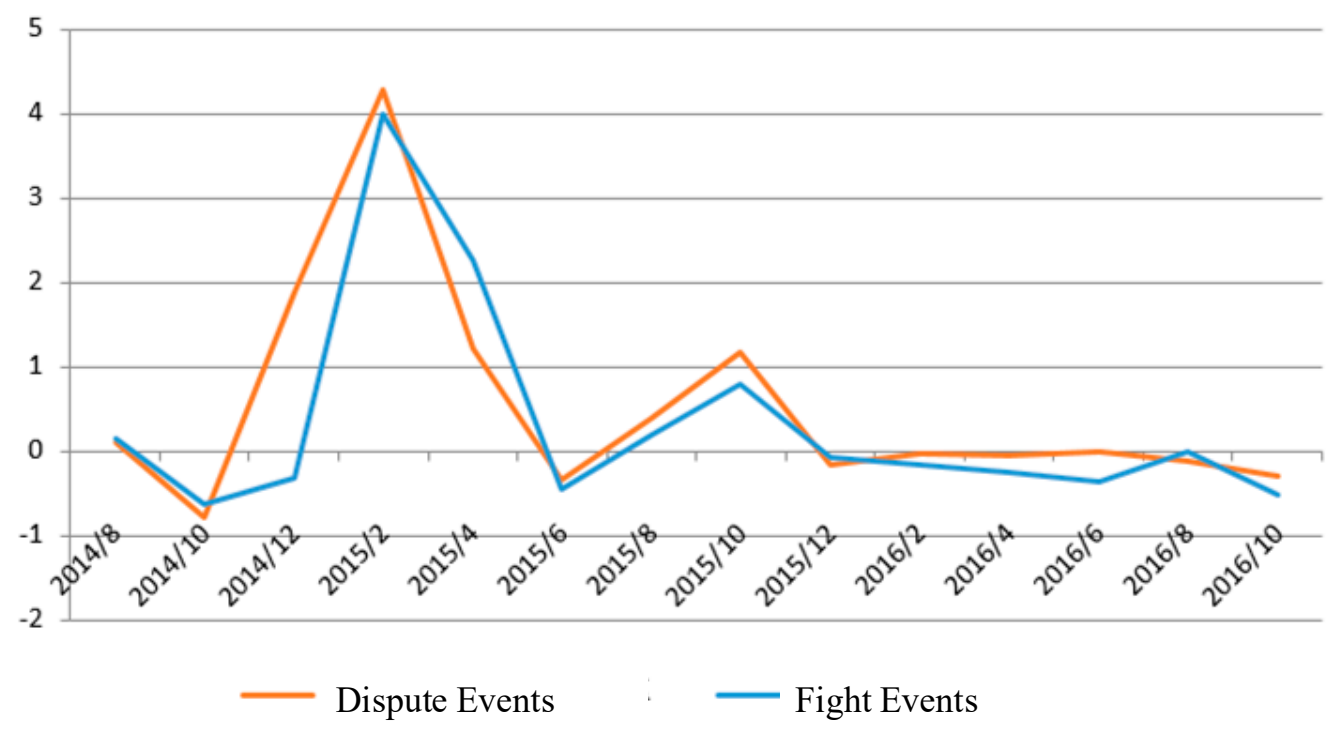

Figure 20. Variance ratio of events of disputes-fights.

Figure 20 shows that the line chart of these two types of events are almost coincident. Thus, these two types of events are considered strongly correlated to temporal distribution. Considering that these two events are relevant in spatial distribution, we conclude that strong correlations exist between contradictions and brawl events in temporal and spatial distributions. Based on the strong temporal and spatial correlations, we conclude that the contradictions and disputes are the important causes of fights and brawls, and they easily evolve into fights if these events are not dealt with well. Therefore, the investigation and mediation of the contradictions and disputes are particularly important in the maintenance of social order.

\section{Discussion}

The concept system of social comprehensive governance is huge and complex, and there are various kinds of events. This paper focuses on the extraction of interesting hot events and the spatio-temporal information mining, which is only one of the many entry points in this field. It has a broad research space in the information mining of the social comprehensive management events based on space-time management, whether in content or method.

First, this study only uses urban social management and comprehensive control events without the other indirect data source. The indirect data from social media can be introduced into later research, which can dig out more information with the comprehensive data together, such as the Weibo and WeChat check-in data.

Second, Ontology is a system for the knowledge representation of all kinds of spatio-temporal phenomena [61]. Our study takes a case study on spatio-temporal data mining with urban social management events to describe the law of urban management. In addition, the system construction of ontology in the urban social management domain requires the participation of experts in the field; the ontology of comprehensive management events constructed in this paper cannot be the real universal ontology because of the limitations of the author. Thus, the ontology constructed in this research has plenty of room for improvement. 
Moreover, the calculation formulas of correlation factors are given in the proposed method of "event-event" and "event-place" correlation exploring in this study. However, the correlations between events cannot be found out intuitively with the correlation factors because of the effect of distance measure units to the calculated values of correlation factors. Therefore, a correction factor is introduced in this study, and its value is related to the distance measure units. The correlation factor requires a great number of tests to verify the relationship between the correction factor and the distance measure units repeatedly to make sure that the relevance between events can be represented intuitively with the correlation factor.

\section{Conclusions}

The purpose of urban management and comprehensive administration is to maintain a good environment for social development. During the process of urban management, there are a large number of work record data. Thus, how to make use of these work records well to excavate useful information hidden in these historical data is very important for the decision-making of further urban social governance. The content of city management is huge with a complicated structure for urban governance. This study puts forward a concept system of urban social management events. An ontology model is proposed for the massive spatio-temporal data mining of social management and comprehensive control events. It designs the process of the construction of the ontology, builds the ontology using the existing tools, and realizes the extraction of the hot events in city management based on the semantic reasoning of ontology with Java-based frameworks, whose comprehensiveness and accuracy are higher than that of the old ones. This paper also introduces the spatio-temporal information mining for discrete USMEs from three perspectives: geographical statics, spatial aggregation and correlation relationship. A spatial-temporal correlation data mining between events and locations or between events and events is proposed to mine the spatial-temporal information from the discrete and massive city's comprehensive management events. Thermodynamic charts scatter plots, and the line charts are used to realize the visualization of the urban social management event model to provide decision support for urban comprehensive management. The USMEs of Qingdao city in August 2016 are taken as an experimental dataset with the proposed approach. The proposed method can effectively mine the management of social hot events and their spatial distribution patterns, which can guide city governance and enhance the city's comprehensive management level. The social media data should be introduced to integrate with the USMEs for the future spatio-temporal data mining of urban management and comprehensive administration.

Author Contributions: X.L. and S.W. designed the experiments and wrote the paper. Q.H. conceived the study; H.W. performed the experiments and analyzed the data.

Funding: This research received no external funding.

Acknowledgments: This research is supported by National Natural Science Foundation of China (Grant No. 41271452) and Key Technologies R\&D Program of China (Grant No. 2015BAK03B04).

Conflicts of Interest: The authors declare no conflict of interest.

\section{References}

1. Bencardino, M.; Nesticò, A. Demographic Changes and Real Estate Values. A Quantitative Model for Analyzing the Urban-Rural Linkages. Sustainability 2017, 9, 536. [CrossRef]

2. Van den Berg, L.; Drewett, R.; Klaasen, L.H. Urban Europe: A Study of Growth and Decline; Elsevier Ltd.: London, UK, 1982.

3. Nestico, A.; Sica, F. The sustainability of urban renewal projects: A model for economic multi-criteria analysis. J. Prop. Invest. Financ. 2017, 35, 397-409. [CrossRef]

4. Wang, J.; Xie, M. Geographical national condition and complex system. Acta Geod. Cartogr. Sin. 2016, 45, 1-8. 
5. Merem, E.C.; Yerramilli, S.; Twumasi, Y.A.; Wesley, J.M.; Robinson, B.; Richardson, C. The Applications of GIS in the Analysis of the Impacts of Human Activities on South Texas Watersheds. Int. J. Environ. Res. Public Health 2011, 8, 2418-2446. [CrossRef] [PubMed]

6. Gao, S.; Janowicz, K.; Couclelis, H. Extracting urban functional regions from points of interest and human activities on location-based social networks. Trans. GIS 2017, 21, 446-467. [CrossRef]

7. Dai, L.; Xue, T.; Wu, B.; Rong, X.; Xu, B. Spatiotemporal Structure Features of Network Check-in Activities of Urban Residents and Their Impacting Factors: A Case Study in Six Urban Districts of Beijing. J. Asian Arch. Build. Eng. 2017, 16, 131-138. [CrossRef]

8. Gore, A. The digital earth: Understanding our planet in the 21st century. Aust. Surv. 1998, 43, 89-91. [CrossRef]

9. Su, K.; Li, J.; Fu, H. Smart city and the applications. In Proceedings of the 2011 International Conference on Electronics, Communications and Control, Ningbo, China, 9-11 September 2011; pp. 1028-1031.

10. Girard, L.F. Toward a Smart Sustainable Development of Port Cities/Areas: The Role of the "Historic Urban Landscape" Approach. Sustainability 2013, 5, 4329-4348. [CrossRef]

11. Li, D. Digital city + Internet of things + cloud computing = smart city. China New Telecommun. 2011, 20, 46.

12. Paganelli, F.; Turchi, S.; Giuli, D. A Web of Things Framework for RESTful Applications and Its Experimentation in a Smart City. IEEE Syst. J. 2017, 10, 1412-1423. [CrossRef]

13. Zhang, K.; Ni, J.; Yang, K.; Liang, X.; Ren, J.; Shen, X.S. Security and Privacy in Smart City Applications: Challenges and Solutions. IEEE Commun. Mag. 2017, 55, 122-129. [CrossRef]

14. Rathore, M.M.; Paul, A.; Ahmad, A.; Jeon, G. IoT-Based Data: From Smart City towards Next Generation Super City Planning. Int. J. Semant. Web Inf. Syst. 2017, 13, 28-47. [CrossRef]

15. Khan, M.S.; Woo, M.; Nam, K.; Chathoth, P.K. Smart City and Smart Tourism: A Case of Dubai. Sustainability 2017, 9, 2279. [CrossRef]

16. Wong, M.S.; Wang, T.; Ho, H.C.; Kwok, C.Y.T.; Lu, K.; Abbas, S. Towards a Smart City: Development and Application of an Improved Integrated Environmental Monitoring System. Sustainability 2018, 10, 623. [CrossRef]

17. Wang, Y.; Wang, T.; Ye, X.; Zhu, J.; Lee, J. Using Social Media for Emergency Response and Urban Sustainability: A Case Study of the 2012 Beijing Rainstorm. Sustainability 2016, 8, 25. [CrossRef]

18. Kuroishi, I. Urban Survey and Planning in Twentieth-Century Japan: Wajiro Kons Modernology and Its Descendants. J. Urban Hist. 2016, 42, 557-581. [CrossRef]

19. Xu, Z.; Zhang, J.; Li, C.; Li, Z.; Rao, Y.; Lu, T. A Road to Sustainable Development of Chinese Cities: A Perception of Improving Urban Management Efficiency Based on Two-Level Production Factors. Sustainability 2017, 9, 2212. [CrossRef]

20. Zhou, M.; Yue, Y.; Li, Q.; Wang, D. Portraying Temporal Dynamics of Urban Spatial Divisions with Mobile Phone Positioning Data: A Complex Network Approach. ISPRS Int. J. Geo Inf. 2016, 5, 240. [CrossRef]

21. Fu, J.Y.; Jing, C.F.; Du, M.Y.; Fu, Y.L.; Dai, P.P. Study on Adaptive Parameter Determination of Cluster Analysis in Urban Management Cases. ISPRS Int. Arch. Photogramm. Remote Sens. Spat. Inf. Sci. 2017, XLII-2/W7, 1143-1150.

22. Mennis, J.; Guo, D. Spatial data mining and geographic knowledge discovery-An introduction. Comput. Environ. Urban Syst. 2009, 33, 403-408. [CrossRef]

23. Chen, C.C.; Chiang, M.F.; Peng, W.C. Mining and clustering mobility evolution patterns from social media for urban informatics. Knowl. Inf. Syst. 2016, 47, 381-403. [CrossRef]

24. Noulas, A.; Scellato, S.; Lathia, N.; Mascolo, C. Mining User Mobility Features for Next Place Prediction in Location-Based Services. In Proceedings of the 2012 IEEE 12th International Conference on Data Mining, Brussels, Belgium, 10-13 December 2012; pp. 1038-1043.

25. Noulas, A.; Scellato, S.; Lathia, N.; Mascolo, C. A Random Walk around the City: New Venue Recommendation in Location-Based Social Networks. In Proceedings of the 2012 International Conference on Privacy, Security, Risk and Trust, Amsterdam, The Netherlands, 3-5 September 2012; pp. 144-153.

26. Ji, B.; Lee, Y.; Yu, K.; Kwon, P. Detecting Themed Streets Using a Location Based Service Application. ISPRS Int. J. Geo Inf. 2016, 5, 111. [CrossRef]

27. Laylavi, F.; Rajabifard, A.; Kalantari, M. A Multi-Element Approach to Location Inference of Twitter: A Case for Emergency Response. ISPRS Int. J. Geo Inf. 2016, 5, 56. [CrossRef] 
28. Hu, Q.; Wang, M.; Li, Q. Urban hotspot and commercial area exploration with check-in Data. Acta Geod. Cartogr. Sin. 2014, 43, 314321.

29. Wang, M.; Hu, Q.; Li, Q.; Qin, L. School of Remote Sensing and Information Engineering, Wuhan University; Shenzhen Key Laboratory of Spatial Smart Sensing and Services, Shenzhen University; State Key Laboratory of Information Engineering in Surveying, Mapping and Remote Sensing, Wuhan University. Extracting hierarchical landmark from check-in data. Chin. J. Comput. 2016, 39, 405-413.

30. Zhang, D.; Zhou, B.; Li, H.; Wang, X.; Si, M. Prediction of Urban Heat Island Expansion based on Markov Chain Theory. China Popul. Resour. Environ. 2013, 23, 321-325.

31. Kazak, J.K. The Use of a Decision Support System for Sustainable Urbanization and Thermal Comfort in Adaptation to Climate Change Actions-The Case of the Wrocław Larger Urban Zone (Poland). Sustainability 2018, 10, 1083. [CrossRef]

32. Ai, H.; Shi, Y. Study on prediction of haze based on BP neural network. Comput. Simul. 2015, 32, $402-405$.

33. Zhao, X.J.; Zhao, P.S.; Xu, J.; Meng, W.; Pu, W.W.; Dong, F.; He, D.; Shi, Q.F. Analysis of a winter regional haze event and its formation mechanism in the North China Plain. Atmos. Chem. Phys. 2013, 13, 5685-5696. [CrossRef]

34. Liu, Z.; Jia, Z.; Li, X. Traffic volume forecast based on gray markov chain model. J. East China Jiaotong Univ. 2012, 29, 30-34.

35. Das, R.D.; Winter, S. Detecting Urban Transport Modes Using a Hybrid Knowledge Driven Framework from GPS Trajectory. ISPRS Int. J. Geo Inf. 2016, 5, 207. [CrossRef]

36. Deng, Z. Transport Service Oriented Muti-Source Mobile Trajectory Data Mining and Muti-Level Knowledge Discovery of Human Activities. Ph.D. Thesis, East China Normal University, Shanghai, China, 2012.

37. Bergman, C.; Oksanen, J. Conflation of OpenStreetMap and Mobile Sports Tracking Data for Automatic Bicycle Routing. Trans. GIS 2016, 20, 848-868. [CrossRef]

38. Zhang, J.; Wu, F.; Zhang, H.; Information Engineering University; Xi'an Surveying and Mapping Information \& Technology Station. Urban residents travel characteristics mining utilizing taxi trajectory data. Geogr. Geo Inf. Sci. 2015, 31, 104-108.

39. Ishikawa, T.; Fujinami, K. Smartphone-Based Pedestrian's Avoidance Behavior Recognition towards Opportunistic Road Anomaly Detection. ISPRS Int. J. Geo Inf. 2016, 5, 182. [CrossRef]

40. Xu, Z.; Liu, Y.; Yen, N.; Mei, L.; Luo, X.; Wei, X.; Hu, C. Crowdsourcing based Description of Urban Emergency Events using Social Media Data. IEEE Trans. Cloud Comput. 2016, 99, 1. [CrossRef]

41. Huang, Q.; Wong, D.W.S. Activity patterns, socioeconomic status and urban spatial structure: What can social media data tell us? Int. J. Geogr. Inf. Syst. 2016, 30, 1873-1898. [CrossRef]

42. Shen, Y.; Karimi, K. Urban function connectivity: Characterisation of functional urban streets with social media check-in data. Cities 2016, 55, 9-21. [CrossRef]

43. Romolini, M.; Grove, J.M.; Locke, D.H. Assessing and comparing relationships between urban environmental stewardship networks and land cover in Baltimore and Seattle. Landsc. Urban Plan. 2013, 120, 190-207. [CrossRef]

44. Du, X.; Emebo, O.; Varde, A.; Tandon, N.; Chowdhury, S.N.; Weikum, G. Air quality assessment from social media and structured data: Pollutants and health impacts in urban planning. In Proceedings of the 2016 IEEE, International Conference on Data Engineering Workshops, Helsinki, Finland, 16-20 May 2016; pp. 54-59.

45. Li, J.; Qin, Q.; Han, J.; Tang, L.-A.; Lei, K.H. Mining Trajectory Data and Geotagged Data in Social Media for Road Map Inference. Trans. GIS 2015, 19, 1-18. [CrossRef]

46. Petrova, M.; Nenko, A.; Sukharev, K. Urban acupuncture 2. In 0: Urban management tool inspired by social media. In Proceedings of the International Conference on Electronic Governance and Open Society: Challenges in Eurasia, St. Petersburg, Russia, 22-23 November 2016; pp. 248-257.

47. Gabrielli, L.; Rinzivillo, S.; Ronzano, F.; Villatoro, D. From Tweets to Semantic Trajectories: Mining Anomalous Urban Mobility Patterns. Lect. Notes Comput. Sci. 2014, 8313, $26-35$.

48. Widhalm, P.; Yang, Y.; Ulm, M.; Athavale, S.; González, M.C. Discovering urban activity patterns in cell phone data. Transportation 2015, 42, 597-623. [CrossRef]

49. Lee, W.H.; Tseng, S.S.; Shieh, J.L.; Chen, H.H. Discovering Traffic Bottlenecks in an Urban Network by Spatiotemporal Data Mining on Location-Based Services. IEEE Trans. Intell. Transp. Syst. 2011, 12, 1047-1056. [CrossRef] 
50. Zhu, B.; Xu, X. Urban Principal Traffic Flow Analysis Based on Taxi Trajectories Mining. In Advances in Swarm and Computational Intelligence; Springer International Publishing: New York, NY, USA, 2015; pp. 172-181.

51. Jin, J.; Gubbi, J.; Marusic, S.; Palaniswami, M. An Information Framework for Creating a Smart City Through Internet of Things. IEEE Int. Things J. 2014, 1, 112-121. [CrossRef]

52. Kim, T.H.; Ramos, C.; Mohammed, S. Smart City and IoT. Future Gener. Comput. Syst. 2017, 76, $159-162$. [CrossRef]

53. Noy, N.F.; Crubézy, M.; Fergerson, R.W.; Knublauch, H.; Tu, S.W.; Vendetti, J.; Musen, M.A. Protégé-2000: An open-source ontology-development and knowledge-acquisition environment. AMIA Annu. Symp. Proc. AMIA Symp. 2003, 2003, 953.

54. Musen, M.A.; Team, T.P. Protégé Ontology Editor. In Encyclopedia of Systems Biology; Springer: New York, NY, USA, 2013; pp. 1763-1765.

55. Ameen, A.; Khan, K.U.R.; Rani, B.P. Extracting knowledge from ontology using Jena for semantic web. In Proceedings of the International Conference for Convergence for Technology-2014, Pune, India, 6-8 April 2014; pp. 1-5.

56. Diosteanu, A.; Cotfas, L.A. Agent Based Knowledge Management Solution using Ontology, Semantic Web Services and GIS. Inform. Econ. J. 2009, 13, 90-98.

57. Giri, K.; Gokhale, P. Developing a banking service ontology using Protégé, an open source software. Annu. Libr. Inf. Stud. 2015, 62, 281-285.

58. Owens, A.; Seaborne, A.; Gibbins, N.; Schraefel, M.C. Clustered TDB: A Clustered Triple Store for Jena. In Proceedings of the 2009 WWW, Madrid, Spain, 20-24 April 2009.

59. Sheather, S.J.; Jones, M.C. A Reliable Data-Based Bandwidth Selection Method for Kernel Density Estimation. J. R. Stat. Soc. 1991, 53, 683-690.

60. Hinneburg, A.; Gabriel, H.H. DENCLUE 2.0: Fast Clustering Based on Kernel Density Estimation. In Advances in Intelligent Data Analysis VII; Springer: Berlin, German, 2007; pp. 70-80.

61. Iwaniak, A.; Łukowicz, J.; Strzelecki, M.; Kaczmarek, I. Ontology Driven Analysis of Spatio-temporal Phenomena, Aimed at Spatial Planning and Environmental Forecasting. In Proceedings of the ISPRS 2013-SSG Conference, Antalya, Turkey, 11-17 November 2013; pp. 119-124. 